\title{
Optimal Monetary Policy in a Micro-founded Model with Parameter Uncertainty
}

\author{
Takeshi Kimura ${ }^{\dagger}$ and Takushi Kurozumi ${ }^{\dagger}$ \\ Bank of Japan
}

December 11, 2003

\begin{abstract}
In this paper, we structurally model uncertainty with a micro-founded model, and investigate its implications for optimal monetary policy. Uncertainty about deep parameters of the model implies that the central bank simultaneously faces both uncertainty about the structural dynamic equations and about the social loss function. Considering both uncertainties with cross-parameter restrictions based on the micro-foundations of the model, we use Bayesian methods to determine the optimal monetary policy that minimizes the expected loss. Our analysis shows how uncertainty can lead the central bank to pursue a more aggressive monetary policy, overturning Brainard's common wisdom. As the degree of uncertainty about inflation dynamics increases, the central bank should place much more weight on price stability, and should respond to shocks more aggressively. In addition, when the central bank is uncertain about output dynamics, an aggressive policy response can be justified by the positive correlation between policy multiplier and transmission of natural rate of interest shock as well as the effect of loss-function uncertainty. We also show that combining a more aggressive policy response with a highly inertial interest rate policy reduces Bayesian risk.
\end{abstract}

JEL Classification: E31, E32, E52.

Keywords: optimal monetary policy, parameter uncertainty, loss-function uncertainty, inertial interest rate policy.

We are grateful for helpful discussions and comments from Kosuke Aoki, Jinill Kim, Michio Kitahara, Andrew Levin, Athanasios Orphanides, David Reifschneider, Eric Swanson, David López-Salido, Robert Tetlow, as well as workshop participants at the Federal Reserve Board. The views expressed herein are those of the authors alone and not necessarily those of the Bank of Japan or the Federal Reserve Board.

$\dagger$ The author is a senior economist at the Bank of Japan, and a visiting economist at the Federal Reserve Board.

Correspondence: Mail Stop 77, Division of Monetary Affairs, Board of Governors of the Federal Reserve System, Washington, D.C. 20551. Tel:202-452-2952, E-mail: takeshi.kimura@frb.gov

* Bank of Japan and Carnegie Mellon University (Pittsburgh, PA 15213) Tel:412-268-7421, E-mail:tkurozum@andrew.cmu.edu 


\section{Introduction}

With the New Keynesian Phillips curve, many recent studies have provided rich implications for the conduct of monetary policy. The New Keynesian Phillips curve can be derived from a variety of supply-side models. ${ }^{1}$ For example, it can be described as the staggered price determination that emerges from a monopolistically competitive firm's optimal behavior in Calvo's (1983) model. Roughly speaking, firms set nominal prices based on the expectations of future marginal costs. However, the New Keynesian Phillips curve has been criticized for failing to match the short-run dynamics exhibited by inflation. ${ }^{2}$ Specifically, inflation seems to respond sluggishly and display significant persistence in the face of shocks, while the New Keynesian Phillips curve allows current inflation to be a jump variable that can respond immediately to any disturbance.

In order to solve this empirical defect of the New Keynesian Phillips curve, several studies have proposed a hybrid Phillips curve while keeping a micro-foundation. ${ }^{3}$ This Phillips curve is a modified inflation adjustment equation which incorporates endogenous persistence by including the lagged inflation rate in the New Keynesian Phillips curve. That is, it nests a purely forward-looking Phillips curve as a particular case, and allows for a fraction of firms that use a backward-looking rule to set prices. Increasing attention has been recently given to the estimation of the hybrid Phillips curve. However, the estimation results vary greatly among studies. ${ }^{4}$ That is, there has not been any empirical consensus about what fraction of firms follow a rule of thumb. This implies that the central bank faces uncertainty about the degree of inflation persistence, which the existing literature has identified as one of the most critical parameters affecting the performance of monetary policy. ${ }^{5}$

\footnotetext{
${ }^{1}$ See Roberts (1995).

2 See, for example, Fuhrer (1997), Mankiw (2001), and Estrella and Fuhrer (2002).

${ }^{3}$ See Galí and Gertler (1999), Amato and Laubach (2003), Steinsson (2003), and Giannoni and Woodford (2003).

${ }^{4}$ See, for example, Fuhrer (1997), Galí and Gertler (1999), Rudebusch (2002), Roberts (2001), Galí et al. (2001), Kimura and Kurozumi (2004), and Giannoni and Woodford (2003).

${ }^{5}$ When inflation dynamics can be described as the purely forward-looking New Keynesian Phillips
} 
In this study, we first investigate how the central bank should conduct monetary policy under uncertainty about inflation persistence. We use Bayesian methods to determine the optimal monetary policy that minimizes the expected social welfare loss, given a prior distribution on some uncertain parameters. This approach, initially started by Brainard (1967), has recently been followed by Estrella and Mishkin (1999), Hall et al. (1999), Martin and Salmon (1999), Svensson (1999), Sack (2000), among others. These studies support Brainard's results that optimal policy should be less aggressive in the face of parameter uncertainty. ${ }^{6}$ One notable exception is Söderström (2002), who finds that uncertainty about inflation persistence leads the central bank to pursue a more aggressive monetary policy. ${ }^{7}$ His analysis is based on a backward-looking model of Svensson (1997) type with the Old Keynesian Phillips curve, and he assumes that the coefficient on lagged inflation in that Phillips curve is allowed to take values different from unity in order to introduce parameter uncertainty.

Instead of a backward-looking model, we use a micro-founded forward-looking model with the hybrid Phillips curve. Because of a micro-foundation, we can structurally model parameter uncertainty. For example, when the central bank faces uncertainty about some structural deep parameters of price-setters, this implies that the central bank is uncertain about both inflation persistence and the slope of the Phillips curve. But, the central bank can impose cross-parameter restrictions on both uncertainties by using information based on the micro-foundation of the model. The micro-foundation suggests that weights of a social loss function are directly related to structural deep parameters. Therefore, uncertainty on some deep parameters makes the central bank face uncertainty about social loss-function weights as well as uncertainty about inflation dynamics. But, again, with the information based on the micro-foundation, the central bank can impose cross-parameter restrictions between

\footnotetext{
curve, price-level targeting performs very well. (See Vestin, 2000). But, Walsh (2003a) suggests that, when current inflation is affected by both expected future inflation and lagged inflation, the performance of price-level targeting deteriorates significantly as the weight on lagged inflation increases. Similarly, Rudebusch (2002) finds that nominal income targeting does well when inflation is forward-looking but poorly when it is more backward-looking.

${ }^{6}$ See Walsh (2003b) for a recent survey about monetary policy under uncertainty.

${ }^{7}$ Craine (1979) also shows that uncertainty about the dynamics of the economy leads to more aggressive policy, albeit in a univariate model.
} 
uncertainty about loss-function weights, uncertainty about inflation persistence, and uncertainty about the slope of the Phillips curve. ${ }^{8}$

In such a setting, we show how uncertainty can lead the central bank to pursue a more aggressive monetary policy, overturning Brainard's conservatism principle. Two conditions that are necessary for Brainard's conservatism principle are violated in our analysis. First, our model is forward-looking and dynamic, whereas the model of Brainard (1967) is static. This distinction is important in the presence of uncertainty about inflation persistence. As discussed by Söderström (2002), when the dynamics of inflation are uncertain, the variances of inflation and output gap increase with the distance from target. Thus, when inflation and output are further away from target, the uncertainty about their future development is greater. Then, it pays to make sure current inflation is very stable by reacting more aggressively to shocks. Second, and especially relevant for our analysis, the traditional applications of Brainard's conservatism principle rely on the assumption that the central bank has a fixed loss function with known weights on the variability of a specific set of target variables. However, when the central bank faces uncertainty about structural deep parameters, this assumption is highly misleading. The micro-foundation of the model suggests that the weights of social loss function are non-linear functions of the structural deep parameters, and when this is the case, the expected weights of loss function change drastically as the degree of uncertainty about deep parameters increases. In the case of uncertainty about inflation-dynamics, the central bank should place higher weight on price stability than in the absence of uncertainty, and respond more aggressively to shocks to stabilize inflation.

We next examine the time path of optimal monetary policy. Throughout our analysis, we assume that the central bank is able to act under commitment. Previous literature suggests that under parameter certainty the central bank should adopt a highly inertial interest rate policy in order to stabilize inflation, when private agents are forward-looking. We confirm that such a principle still holds under parameter

\footnotetext{
${ }^{8}$ Levin and Williams (2003) incorporate the same aspect into an analysis of uncertainty about loss-function weights.
} 
uncertainty, and show that combining a more aggressive policy response with a highly inertial interest rate policy reduces Bayesian risk. This result is completely opposite to the result suggested by previous literature. With a backward-looking model, Söderström (2002) finds that the central bank should return to a neutral stance soon after the bank initially responds to the shocks aggressively, since the strong initial move has neutralized a larger part of the shock. However, such a policy response is not desirable, when private agents are forward-looking. If the central bank commits to initially respond to shocks aggressively, but then soon returns to a neutral stance, the bank cannot stabilize the current output gap and thus inflation very much. Instead, by exploiting the expectations of the private sector and committing to an aggressive and inertial policy, the central bank can stabilize the economy more effectively under uncertainty.

To confirm that our results do not depend on the specific model, we conduct the robustness analysis with alternative models which explain inflation inertia. The hybrid Phillips curve in our main analysis is based on Galí and Gertler (1999) and Amato and Laubach (2003). We apply our analysis to the alternative hybrid Phillips curves (and hence alternative loss functions) suggested by Steinsson (2003) and Giannoni and Woodford (2003). ${ }^{9}$ Steinsson (2003) proposes a more general specification of rule-of-thumb price setting than our baseline model. On the other hand, Giannoni and Woodford (2003) propose an indexation approach to explain inflation inertia, which differs from the rule-of-thumb approach. With these alternative models, we again find that optimal policy response under uncertainty becomes more aggressive than under certainty equivalence.

Finally, we apply our Bayesian approach to the case of uncertainty about output dynamics. In this analysis, we use a modified IS curve which nests a purely forward-looking IS curve as a particular case, and allows for a fraction of consumers that use a backward-looking rule to decide their spending. We assume that central bank is uncertain about the degree of endogenous persistence of output, which depends on the weight of the rule-of-thumb consumers. We again find a more aggressive policy

\footnotetext{
${ }^{9}$ We are grateful to Andrew Levin for suggesting this robustness analysis.
} 
response is needed under uncertainty about output dynamics, and show that such an aggressive response can be justified by the positive correlation between policy multiplier and transmission of natural rate of interest shock as well as the effect of loss-function uncertainty. The positive correlation between policy multiplier and transmission of shocks is also based on the micro-foundation of the model, and this correlation has been ignored in most of the existing literature that confirms Brainard's conservatism principle.

The outline of the remainder of the paper is as follows. Section 2 presents the model of the economy. Section 3 poses the problem of optimal monetary policy under uncertainty about structural deep parameters of price-setters. Section 4 presents the simulation results of the model and quantitative analysis of optimal policy. Section 5 examines the robustness of our results with alternative models explaining inflation inertia. Section 6 poses the problem of optimal monetary policy under uncertainty about structural deep parameters of consumers. Section 7 offers conclusions.

\section{A Simple Optimizing Model for Monetary Policy Analysis}

In this section, we review a simple optimizing model with known parameters that underlies the structural equations and the social welfare function. The model is closely related to models discussed in Woodford (1999,2003), Giannoni (2000,2002), Amato and Laubach (2003), and Steinsson (2003). We first describe the IS equation, and then turn to the Phillips curve. Finally, we describe the social welfare function.

\subsection{IS curve}

There is a continuum of consumer-producers, each of them indexed by the product $i \in[0,1]$ of which it is the monopolistic producer. Household $i$ 's objective is to maximize

$$
E_{0} \sum_{t=0}^{\infty} \beta^{t}\left[u\left(C_{t}^{i} ; \xi_{t}\right)+\chi\left(M_{t}^{i} / P_{t} ; \xi_{t}\right)-v\left(y_{t}(i) ; \xi_{t}\right)\right]
$$


where $\beta \in(0,1)$ is the household's discount factor, $C_{t}^{i}$ is household $i$ 's consumption of the usual Dixit-Stiglitz aggregate, $P_{t}$ is the corresponding price index, $M_{t}^{i}$ is the amount of money balances held at the end of period $t$, and $y_{t}(i)$ is the household's supply of its good. The vector-valued random disturbance $\xi$ in (1) represents taste shifters affecting the utility of consumption, $u\left(\cdot ; \xi_{t}\right)$, the utility of real money balances, $\chi\left(\cdot ; \xi_{t}\right)$, and the disutility of supply, $v\left(\cdot ; \xi_{t}\right)$. For each value of $\xi$, the functions $u\left(\cdot ; \xi_{t}\right)$ and $\chi\left(\cdot ; \xi_{t}\right)$ are assumed to be increasing and concave, while $v\left(\cdot ; \xi_{t}\right)$ is increasing and convex.

Expenditure minimization and market clearing imply that the demand for each good $i$ is given by

$$
y_{t}(i)=\left(\frac{p_{t}(i)}{P_{t}}\right)^{-\theta} Y_{t} .
$$

Here, $p_{t}(i)$ denotes the price that household $i$ charges per unit of its product, $\theta$ denotes the elasticity of substitution between products, and $Y_{t}$ denotes the aggregate of individual household's output.

Each household maximizes (1) over the sequence $\left\{C_{t}^{i}, M_{t}^{i}\right\}$, subject to its budget constraint. In formulating the household's budget constraint, we assume that financial markets are complete so that risks are efficiently shared. Then, it follows that all households face an identical intertemporal budget constraint, and choose identical state-contingent plans for consumption and money balances.

Taking a log-linear approximation of the first-order condition characterizing the optimal consumption and combining it with the goods market clearing condition lead to the following IS equation.

$$
\begin{gathered}
x_{t}=E_{t}\left[x_{t+1}\right]-\sigma^{-1}\left(i_{t}-E_{t}\left[\pi_{t+1}\right]-r_{t}^{n}\right), \\
\text { where } r_{t}^{n} \equiv \sigma E_{t}\left[y_{t+1}^{n}-y_{t}^{n}-\left(g_{t+1}-g_{t}\right)\right] .
\end{gathered}
$$

Here, $x_{t} \equiv y_{t}-y_{t}^{n}$ denotes the output gap, where $y_{t}$ is the percent deviation of aggregate output from its steady-state level, and $y_{t}^{n}$ is the "natural rate of output", the level of output that would obtain if prices were completely flexible. ${ }^{10} \pi_{t}$ is the growth

\footnotetext{
${ }^{10}$ Natural rate of output can be defined as follows:
} 
rate of the aggregate price index, i.e. $\pi_{t} \equiv \log \left(P_{t} / P_{t-1}\right)$, and $i_{t}$ is the nominal interest rate. ${ }^{11} r_{t}^{n}$ is the "natural rate of interest", the real interest rate that would obtain if all prices were flexible, and that would correspond to the equilibrium nominal interest rate in the case of price stability. The parameter $\sigma^{-1}$ measures the intertemporal elasticity of substitution in consumption. The term $g_{t}$ represents variation in spending that is not caused by changes in the real interest rate, such as disturbances to the marginal utility of consumption caused by fluctuations in $\xi_{t} \cdot{ }^{12}$

\subsection{Phillips Curve}

Monetary policy has real effects in this model because prices do not respond immediately to perturbations. Specifically, we assume as in Calvo (1983) that each period only a fraction $1-\alpha$ of suppliers is offered the opportunity to choose a new price, while the remaining suppliers have to maintain whichever price they charged before. Suppliers are drawn randomly and independent of their own history, in particular, regardless of the time elapsed since the last change. In addition, following Galí and Gertler (1999) and Amato and Laubach (2003), we allow for a fraction of agents that use a simple rule of thumb to make their decisions, and depart from the standard Calvo framework. The rule-of-thumb behavior by a fraction of agents can be justified by the existence of optimization costs. Optimization costs lead a fraction of agents to deviate from behaving optimally each period, and to use a simple rule of thumb as an alternative to optimization.

We assume that at the beginning of each period those agents who offered the opportunity to reset their price learn whether they are choosing a new price by solving their optimization problem, or by using the rule of thumb instead. Specifically, whenever a supplier finds itself changing its price, with probability $\lambda$ it will set the

$$
\begin{gathered}
y_{t}^{n} \equiv(\sigma+\omega)^{-1}\left(\sigma g_{t}+\omega z_{t}\right) \\
\text { where } g_{t} \equiv-\frac{u_{c \xi}\left(Y^{*} ; 0\right)}{u_{c c}\left(Y^{*} ; 0\right) Y^{*}} \xi_{t}, \quad z_{t} \equiv-\frac{v_{y \xi}\left(Y^{*} ; 0\right)}{v_{y y}\left(Y^{*} ; 0\right) Y^{*}} \xi_{t}, \sigma \equiv-\frac{u_{c c}\left(Y^{*} ; 0\right) Y^{*}}{u_{c}\left(Y^{*} ; 0\right)}, \omega \equiv \frac{v_{y y}\left(Y^{*} ; 0\right) Y^{*}}{v_{y}\left(Y^{*} ; 0\right)} .
\end{gathered}
$$

${ }^{11}$ More specifically, all log-linearizations are taken around a steady state with zero inflation. Hence, $\pi_{t}$ is by definition the percent deviation from its steady-state value, while $i_{t}$ denotes the percent deviation of the interest rate from its steady-state value associated with zero inflation.

${ }^{12}$ See footnote 10 . 
price optimally, and with probability $1-\lambda$ it will set the price at $p_{t}^{r}$, following the simple rule of thumb

$$
p_{t}^{r}=P_{t-1}^{*} \cdot \frac{P_{t-1}}{P_{t-2}}
$$

where $P_{t}^{*}$ is the aggregate of the prices newly chosen in period $t$ by both optimizing and rule-of-thumb price setters. The rule (5) has the property that it relies on prices chosen by optimizing price setters in the previous period.

Since every supplier faces the same demand function (2), all optimizing suppliers chosen in period $t$ to adjust their price will choose the same price, $p_{t}^{o}$, which maximizes the expected present discounted profits

$$
E_{t}\left\{\sum_{j=0}^{\infty}(\alpha \beta)^{j}\left[\frac{u_{c}\left(Y_{t+j} ; \xi_{t+j}\right)}{P_{t+j}} Y_{t+j}\left(\frac{p_{t}^{o}}{P_{t+j}}\right)^{-\theta} p_{t}^{o}-v\left(Y_{t+j}\left(\frac{p_{t}^{o}}{P_{t+j}}\right)^{-\theta} ; \xi_{t+j}\right)\right]\right\} .
$$

The first term in brackets represents the household's utility of consumption in period $t+j$ if it chooses price $p_{t}^{o}$ in the current period. It is the product of marginal utility of consumption at date $t^{+} j$ and total revenues from sales at price $p_{t}^{o}$. The second term represents the household's disutility of providing the amount of goods demanded at period $t+j$. The discount factor for these streams of utility is adjusted for the fact the price chosen at date $t$ remains in effect at date $t+j$ with probability $\alpha^{j}$. Log-linearizing the first-order conditions to the above problem and using the law of motion of the price level, we obtain the following hybrid Phillips curve.

$$
\begin{gathered}
\pi_{t}=\gamma_{b} \pi_{t-1}+\gamma_{f} E_{t}\left[\pi_{t+1}\right]+\widetilde{\kappa} x_{t}, \\
\text { where } \gamma_{b} \equiv \frac{1-\lambda}{\alpha+(1-\lambda)\{1-\alpha(1-\beta)\}}, \\
\gamma_{f} \equiv \frac{\alpha \beta}{\alpha+(1-\lambda)\{1-\alpha(1-\beta)\}}, \\
\widetilde{\kappa} \equiv \gamma_{\kappa} \kappa, \gamma_{\kappa} \equiv \frac{\alpha \lambda}{\alpha+(1-\lambda)\{1-\alpha(1-\beta)\}}, \kappa \equiv \frac{(1-\alpha)(1-\alpha \beta)(\sigma+\omega)}{\alpha(1+\theta \omega)} .
\end{gathered}
$$

Here, the parameter $\omega$ measures the elasticity of the disutility function $v .{ }^{13}$ In the case

\footnotetext{
${ }^{13}$ See footnote 10 .
} 
that all price setters are optimizing, i.e. $\lambda=1$, (7) reduces to the so-called "New Keynesian Phillips Curve"

$$
\pi_{t}=\beta E_{t}\left[\pi_{t+1}\right]+\kappa x_{t}
$$

Changes in the parameter $\lambda$ affect two elements of the model. First, smaller values of $\lambda$ increase the degree of endogenous inflation persistence by increasing $\gamma_{b}$ and decreasing $\gamma_{f}$. That is, the importance of the lagged inflation relative to expected inflation increases. Second, smaller values of $\lambda$ reduce the sensitivity of current inflation to fluctuations in the current output gap by reducing $\widetilde{\kappa}$. This is because fewer price setters take the expected future output gaps into account when resetting their prices.

\subsection{Social Welfare Function}

Following Amato and Laubach (2003) and Woodford (2003), we can derive a second-order Taylor series approximation to the representative household's welfare. Specifically, social welfare can be expressed in the form of a loss function

$$
\begin{gathered}
W=E_{0} \sum_{t=0}^{\infty} \beta^{t}\left[\pi_{t}^{2}+w_{x} x_{t}^{2}+w_{\Delta \pi}\left(\pi_{t}-\pi_{t-1}\right)^{2}+w_{i} i_{t}^{2}\right], \\
\text { where } w_{x} \equiv \frac{\kappa}{\theta}, \quad w_{\Delta \pi} \equiv \frac{1-\lambda}{\alpha \lambda} .
\end{gathered}
$$

As in most studies, social welfare losses depend on the variability of both inflation and output gap. In addition, in our model, the variability of the change in inflation and the variability of nominal interest rates also create welfare losses.

The presence of the change in inflation in the loss function results from the fact that a fraction $1-\lambda$ of price setters is learning about the optimal price by observing the average prices set in the previous period. Note that the weight on the social loss caused by the variability of the change in inflation, $w_{\Delta \pi}$, is a non-linear function of the parameter $\lambda$. Therefore, as the parameter $\lambda$ declines, this weight increases non-linearly.

The presence of the interest rate in the loss function results partly from transactions frictions. Friedman (1969) has argued that high nominal interest rates involve welfare costs of transactions. Whenever the deadweight loss is a convex function of the 
distortion, it is desirable to reduce not only the level but also the variability of the nominal interest rate. As Woodford (2003) suggests, such a loss criterion can be obtained as a second-order approximation to the household's utility function (1) in which real balances are included. ${ }^{14}$ In addition, the variability of the nominal interest rate should be included in the loss function when one takes into account the fact that the nominal interest rate faces a zero lower bound. Rotemberg and Woodford (1997) emphasize that for a sufficiently variable process $\left\{r_{t}^{n}\right\}$, perfect stabilization of the output gap requires interest-rate variability sufficiently high so that a positive steady-state rate of inflation is necessary to avoid the zero lower bound on nominal interest rates, and that such a steady-state inflation is welfare reducing due to its effects on relative price dispersion.

\section{Optimal Monetary Policy under Parameter Uncertainty}

\subsection{Uncertainty about Inflation Persistence and Loss Function}

Recently, a lot of empirical attention has been given to the hybrid Phillips curve (7). However, the empirical estimates of the degree of inflation persistence, that is, the parameter $\gamma_{b}$ and $\gamma_{f}$, have been subject to controversy. Fuhrer (1997) statistically rejects the importance of forward-looking behavior (suggesting $\gamma_{b}=1$ ), although he acknowledges that inflation dynamics without forward-looking behavior are implausible. Rudebusch (2002) estimates $\gamma_{b}$ to equal 0.71, and Roberts (2001) suggests a range for $\gamma_{b}$ of between 0.5 and 0.7. Although Rudebusch and Roberts statistically reject the purely backward-looking Phillips curve, their estimates suggest the weight of backward-looking behavior is larger than that of forward-looking behavior. In contrast, the estimates of Galí et al. (2001) for $\gamma_{b}$ are between 0.03 and

\footnotetext{
${ }^{14}$ In this case, the weight on the social losses caused by the variability in the nominal interest rates, $w_{i}$, is given by

$$
w_{i} \equiv \frac{(1-\alpha)(1-\alpha \beta)}{\alpha \theta(1+\omega \theta)} \frac{\eta_{i}}{\bar{v}},
$$

where $\eta_{i}$ is the elasticity of money demand with respect to the interest rate, and $\bar{v}$ is steady-state velocity of money.
} 
0.27 with Euro area data, and about 0.35 with US data, suggesting that the weight of forward-looking behavior is greater than that of backward-looking behavior. Kimura and Kurozumi (2004) also estimate $\gamma_{b}$ to equal 0.35 with Japan's data. At the extreme, Galí and Gertler (1999) conclude that inflation persistence is rather unimportant and that the purely forward-looking Phillips curve is a reasonable first approximation to data (suggesting $\gamma_{b}=0$ ).

These different estimation results imply that the central bank is uncertain about what fraction of price-setters follow a rule of thumb. Here, we assume that the central bank knows the structure of the economy, the natural rate of output $y_{t}^{n}$, the natural rate of interest $r_{t}^{n}$, and all the structural deep parameters except $\lambda$. Since the information on the parameter $\lambda$ is not included in the central bank's information set $\Omega_{t}^{C B}$, i.e. $\lambda \notin \Omega_{t}^{C B}$, neither are the following parameters.

$$
\begin{gathered}
\gamma_{b} \equiv \frac{1-\lambda}{\alpha+(1-\lambda)\{1-\alpha(1-\beta)\}} \notin \Omega_{t}^{C B}, \gamma_{f} \equiv \frac{\alpha \beta}{\alpha+(1-\lambda)\{1-\alpha(1-\beta)\}} \notin \Omega_{t}^{C B}, \\
\gamma_{\kappa} \equiv \frac{\alpha \lambda}{\alpha+(1-\lambda)\{1-\alpha(1-\beta)\}} \notin \Omega_{t}^{C B}, \\
w_{\Delta \pi} \equiv \frac{1-\lambda}{\alpha \lambda} \notin \Omega_{t}^{C B} .
\end{gathered}
$$

That is, when the central bank is uncertain about what fraction of agents follow a rule of thumb, the bank faces two different types of uncertainty: 1) uncertainty about inflation dynamics (13); 2) uncertainty about the social welfare function (14). As shown in (13)(14), the microeconomic foundations of the model allow us to structurally model uncertainty, which means that cross-parameter restrictions between two different types of uncertainty can be imposed through the unknown parameter $\lambda$. Although in this section we focus the parameter uncertainty about $\lambda$ only, it can provide a very rich analysis on monetary policy under uncertainty.

We assume that the central bank has a prior belief on the distribution of the parameter $\lambda$ :

$$
E_{t}^{C B}[\lambda] \equiv E\left[\lambda \mid \Omega_{t}^{C B}\right] \equiv \bar{\lambda}, V_{t}^{C B}[\lambda] \equiv V\left[\lambda \mid \Omega_{t}^{C B}\right] \equiv v_{\lambda}
$$

Here, the parameter $\lambda$ is assumed to be an i.i.d. random variable. Furthermore, the 
realizations of the parameter $\lambda$ are assumed to be drawn from the same distribution in each period, so issues of learning are disregarded in our analysis. With the prior belief (15) and its own information set $\Omega_{t}^{C B}$, the central bank conducts monetary policy under both uncertainty about inflation dynamics and uncertainty about loss function.

\subsection{Optimal Policy Plan under Uncertainty}

Throughout our analysis, we assume that the central bank is able to act under commitment. As a lot of previous literature suggests, commitment policy allows the central bank to achieve good performance by taking advantage of the effect of credible commitment on the way the private sector forms expectations of future variables. The objective of the central bank is to minimize the social welfare loss (12) with its own information set $\Omega_{t}^{C B}$ and its prior belief on the distribution of the parameter $\lambda$.

In order to illustrate why certainty equivalence no longer holds in our model, it is instructive to take expectations of social welfare loss (12) conditional on $\Omega_{0}^{C B}$ and to rearrange it as follows. ${ }^{15}$

$$
\begin{aligned}
E_{0}^{C B}[W] \equiv E_{0}^{C B}\left[\begin{array}{l}
\pi_{0}^{2}+w_{x} x_{0}^{2}+\bar{w}_{\Delta \pi}\left(\pi_{0}-\pi_{-1}\right)^{2}+w_{i} i_{0}^{2} \\
+\sum_{t=1}^{\infty} \beta^{t} E_{t-1}^{C B}\left[E_{t}^{C B}\left(\pi_{t}^{2}+w_{x} x_{t}^{2}+w_{\Delta \pi}\left(\pi_{t}-\pi_{t-1}\right)^{2}+w_{i} i_{t}^{2}\right)\right]
\end{array}\right] \\
=E_{0}^{C B}\left[\begin{array}{l}
\pi_{0}^{2}+w_{x} x_{0}^{2}+\bar{w}_{\Delta \pi}\left(\pi_{0}-\pi_{-1}\right)^{2}+w_{i} i_{0}^{2} \\
\left.+\sum_{t=1}^{\infty} \beta^{t}\left(\begin{array}{l}
\left(E_{t-1}^{C B}\left[\pi_{t}\right]\right)^{2}+V_{t-1}^{C B}\left[\pi_{t}\right]+w_{x}\left(E_{t-1}^{C B}\left[x_{t}\right]\right)^{2}+w_{x} V_{t-1}^{C B}\left[x_{t}\right] \\
+\bar{w}_{\Delta \pi}\left(E_{t-1}^{C B}\left[\pi_{t}-\pi_{t-1}\right]\right)^{2}+\bar{w}_{\Delta \pi} V_{t-1}^{C B}\left[\pi_{t}-\pi_{t-1}\right]
\end{array}\right)\right]
\end{array}\right] \\
=E_{0}^{C B}\left[\begin{array}{l}
\pi_{0}^{2}+w_{x} x_{0}^{2}+\bar{w}_{\Delta \pi}\left(\pi_{0}-\pi_{-1}\right)^{2}+w_{i} i_{0}^{2}+\beta\left\{\left(1+\bar{w}_{\Delta \pi}\right) V_{0}^{C B}\left[\pi_{1}\right]+w_{x} V_{0}^{C B}\left[x_{1}\right]\right\} \\
+\sum_{t=1}^{\infty} \beta^{t}\left(\begin{array}{l}
\left(E_{t-1}^{C B}\left[\pi_{t}\right]\right)^{2}+w_{x}\left(E_{t-1}^{C B}\left[x_{t}\right]\right)^{2}+\bar{w}_{\Delta \pi}\left(E_{t-1}^{C B}\left[\pi_{t}-\pi_{t-1}\right]\right)^{2}+w_{i} i_{t}^{2} \\
+\beta\left\{\left(1+\bar{w}_{\Delta \pi}\right) V_{t}^{C B}\left[\pi_{t+1}\right]+w_{x} V_{t}^{C B}\left[x_{t+1}\right]\right\}
\end{array}\right],
\end{array}\right.
\end{aligned}
$$

where $\bar{w}_{\Delta \pi} \equiv E_{t}^{C B}\left[w_{\Delta \pi}\right]$. The third equation shows that the expected value of social welfare depends on not only the future deviations of the expected state variables from their targets, but also their variances. The central bank's prior belief leads to the

\footnotetext{
${ }^{15}$ At time $t$, under uncertainty about the parameter $\lambda$, the central bank tries to set its interest rate instrument with its prior belief. In our setting, then, inflation, output gap and interest rate are simultaneously and instantaneously determined at time $t$. In this sense, endogenous variables at time $t$ are included in the central bank's information set $\Omega_{t}^{C B}$.
} 
conditional variances of the inflation rate and output gap as follows.

$$
\begin{aligned}
& V_{t}^{C B}\left[\pi_{t+1}\right]=v_{\lambda} \beta^{-2}\left\{\left(\alpha^{-1}-1+\beta\right) \pi_{t}-\alpha^{-1} \pi_{t-1}+\kappa x_{t}\right\}^{2}+\text { t.i.p. } \\
& V_{t}^{C B}\left[x_{t+1}\right]=\sigma^{-2} V_{t}^{C B}\left[\pi_{t+1}\right]+t . i . p .
\end{aligned}
$$

The notation t.i.p. stands for terms that are independent of monetary policy. When the parameter $\lambda$ is known, i.e. $v_{\lambda}=0$, the conditional variances of endogenous variables are independent of the state of the economy, thus, independent of monetary policy. Therefore, although the expected value of social welfare depends on the conditional variances of endogenous variables, optimal policy cannot affect these variances. Consequently, optimal policy is independent of the degree of uncertainty in the economy, so policy is certainty equivalent. In contrast, when the parameter $\lambda$ is uncertain, i.e. $v_{\lambda}>0$, the conditional variances of the inflation rate and output gap depend on the state of the economy, so they can be affected by monetary policy. Optimal monetary policy will then minimize not only the future deviations of the expected state variables from their targets, but also their variances. Thus, certainty equivalence ceases to hold, and optimal monetary policy depends crucially on the degree of uncertainty on rule-of-thumb behavior.

There is another reason why certainty equivalence ceases to hold. The expected weight that the central bank should place on the variability of the change in inflation, i.e. $\bar{w}_{\Delta \pi} \equiv E_{t}^{C B}\left[w_{\Delta \pi}\right]$, depends on the degree of uncertainty. This is because the weight $w_{\Delta \pi}$ is a non-linear function of the parameter $\lambda$.

$$
\bar{w}_{\Delta \pi} \equiv E_{t}^{C B}\left[w_{\Delta \pi}\right]=E_{t}^{C B}\left[\frac{1-\lambda}{\alpha \lambda}\right]=\frac{1}{\alpha}\left(E_{t}^{C B}\left[\frac{1}{\lambda}\right]-1\right)
$$

As shown in the next section, given a mean of $\lambda$, larger values of $v_{\lambda}$ generally increases $\bar{w}_{\Delta \pi}$. That is, as the degree of uncertainty on rule-of-thumb behavior increases, the central bank should place higher weight on the variability of the change in inflation than the weight in the absence of uncertainty.

We finally turn to the determination of an optimal policy plan. The objective of the central bank is to minimize (16) with respect to the endogenous variables subject to conditional variances (17)(18) and the following constraints.

$$
x_{t}=E_{t}^{C B}\left[x_{t+1}\right]-\sigma^{-1}\left(i_{t}-E_{t}^{C B}\left[\pi_{t+1}\right]-r_{t}^{n}\right),
$$




$$
\begin{array}{r}
\pi_{t}=\bar{\gamma}_{b} \pi_{t-1}+\bar{\gamma}_{f} E_{t}^{C B}\left[\pi_{t+1}\right]+\bar{\gamma}_{\kappa} \kappa x_{t}, \\
\text { where } \bar{\gamma}_{b} \equiv \frac{1-\bar{\lambda}}{\alpha+(1-\bar{\lambda})\{1-\alpha(1-\beta)\}}, \\
\bar{\gamma}_{f} \equiv \frac{\alpha \beta}{\alpha+(1-\bar{\lambda})\{1-\alpha(1-\beta)\}}, \\
\bar{\gamma}_{\kappa} \equiv \frac{\alpha \bar{\lambda}}{\alpha+(1-\bar{\lambda})\{1-\alpha(1-\beta)\}} .
\end{array}
$$

The equations (20) (21) are obtained by taking expectations of IS curve (3) and Phillips curve (7) conditional on the central bank's information set $\Omega_{t}^{C B} \cdot{ }^{16}$ As shown in Appendix A, by deriving the first-order conditions with respect to $\pi_{t}, x_{t}$ and $i_{t}$, we obtain the law of motion for the interest rate implicit in the optimal plan, i.e. the interest rate rule which would implement the optimal plan:

$$
\begin{aligned}
i_{t}= & A_{1} E_{t}^{C B}\left[i_{t+1}\right]+A_{2} i_{t-1}+A_{3} i_{t-2}+A_{4} E_{t}^{C B}\left[\pi_{t+1}\right]+A_{5} \pi_{t}+A_{6} \pi_{t-1}+A_{7} \pi_{t-2} \\
& +A_{8} E_{t}^{C B}\left[x_{t+1}\right]+A_{9} x_{t}+A_{10} x_{t-1}
\end{aligned}
$$

Here, $A_{i}(1 \leq i \leq 10)$ is the parameter which depends on the structural deep parameters and the central bank's prior belief (i.e. $\bar{\lambda}$ and $v_{\lambda}$ ). This policy "rule" nests several types of rules, which previous studies derive, as a special case. For example, when all the structural parameters are known, (22) reduces to the rule that Amato and Laubach (2003) derive, whose form is the same as (22) but each parameter $A_{i}$ is different from (22). In addition, when all price setters are optimizing, i.e. $\lambda=1,(22)$ reduces to the following simple rule:

$$
i_{t}=A_{2} i_{t-1}+A_{3} i_{t-2}+A_{5} \pi_{t}+A_{9}\left(x_{t}-x_{t-1}\right),
$$

which Giannoni (2000) derives.

\footnotetext{
${ }^{16}$ Taking expectations of Phillips curve (7) conditional on the central bank's information set $\Omega_{t}^{C B}$ leads to

$$
\pi_{t}=E_{t}^{C B}\left[\gamma_{b}\right] \pi_{t-1}+E_{t}^{C B}\left[\gamma_{f}\right] \cdot E_{t}^{C B}\left[E_{t}\left(\pi_{t+1}\right)\right]+\operatorname{Cov}_{t}^{C B}\left[\gamma_{f}, E_{t}\left(\pi_{t+1}\right)\right]+E_{t}^{C B}[\tilde{\kappa}] x_{t} .
$$
}

The third term on the right-hand side can be rearranged as follows.

$$
\begin{aligned}
& \operatorname{Cov}_{t}^{C B}\left[\gamma_{f}, E_{t}\left(\pi_{t+1}\right)\right]=\operatorname{Cov}_{t}^{C B}\left[\gamma_{f}, \frac{1}{\gamma_{f}} \pi_{t}-\frac{\gamma_{b}}{\gamma_{f}} \pi_{t-1}-\frac{\tilde{\kappa}}{\gamma_{f}} x_{t}\right] \\
& =\pi_{t}\left(1-E_{t}^{C B}\left[\gamma_{f}\right] \cdot E_{t}^{C B}\left[\frac{1}{\gamma_{f}}\right]\right)-\pi_{t-1}\left(E_{t}^{C B}\left[\gamma_{b}\right]-E_{t}^{C B}\left[\gamma_{f}\right] \cdot E_{t}^{C B}\left[\frac{\gamma_{b}}{\gamma_{f}}\right]\right)-x_{t}\left(E_{t}^{C B}[\tilde{\kappa}]-E_{t}^{C B}\left[\gamma_{f}\right] \cdot E_{t}^{C B}\left[\frac{\tilde{\kappa}}{\gamma_{f}}\right]\right)
\end{aligned}
$$

Substituting this conditional covariance into the above equation and then rearranging the resulting equation yields (21). 


\section{The Effects of Uncertainty about Inflation Dynamics on Optimal Policy}

In this section, we examine how the degree of uncertainty affects the optimal policy response for a given mean of the parameter $\lambda$. We report results for $E_{t}^{C B}[\lambda] \equiv \bar{\lambda}=0.75,0.5,0.25$. Before proceeding to analyze the properties of optimal policy under uncertainty, we discuss how we calibrate the model.

\subsection{Calibration and Central Bank's Prior Belief}

IS curve (3) and Phillips curve (7) contain five known structural parameters $(\alpha, \beta, \sigma, \omega$, $\theta$ ), for which values must be specified. These parameters are chosen to equal those used by Woodford (2003), which he obtained based on the estimation results of Rotemberg and Woodford (1997). That is, $\alpha=0.66 /$ quarter, $\beta=0.99$ /quarter, $\sigma=0.157$, $\omega=0.473$, and $\theta=7.88$. Furthermore, the social loss function (12) depends on the weight on nominal interest rate variability, $w_{i}$. We choose alternative values for $w_{i}, 0.236$ and 0.077 , to assess the robustness of our results. The weight $w_{i}=0.236$ reflects the concern for interest rate variability in Rotemberg and Woodford's model, which is due to the zero lower bound on nominal interest rates. The weight $w_{i}=0.077$ is the implied weight on welfare losses resulting from interest rate variability due to monetary transactions frictions, as calibrated by Woodford (2003). With regard to the natural rate of interest $r_{t}^{n}$, we assume that its process follows a stationary first-order autoregressive process, with mean of zero, standard deviation of $0.93 \%$ /quarter and serial correlation coefficient of 0.35 . This specification is again equal to Woodford's value.

Since we allow the parameter $\lambda$ to lie anywhere in the interval $[0,1]$, we assume that the central bank's prior belief about $\lambda$ formed with a beta distribution, whose probability densities of continuous random variables take on values in the interval $[0,1]$. The density function of a beta-distributed random variable $\lambda$ is given by

$$
f(\lambda)=f(\lambda ; a, b)=\frac{1}{\int_{0}^{1} \lambda^{a-1}(1-\lambda)^{b-1} d \lambda} \lambda^{a-1}(1-\lambda)^{b-1},
$$

where $a>0, \quad b>0$. The mean is $E[\lambda]=a /(a+b)$, and the variance is 
$V[\lambda]=a b /(a+b+1)(a+b)^{2}$. This functional form with a two-parameter family of density is extremely flexible in the shape it will accommodate. (See Figure1.) It is symmetric if $a=b$, asymmetric otherwise, and can be hump-shaped or U-shaped. ${ }^{17}$

When the central bank's prior belief on the parameter $\lambda$ is based on the beta distribution with mean $\bar{\lambda}$ and variance $v_{\lambda}$, the expected weight on the social loss caused by the variability of the change in inflation is given as follows. ${ }^{18}$

$$
\bar{w}_{\Delta \pi} \equiv E_{t}^{C B}\left[w_{\Delta \pi}\right]=\frac{(1-\bar{\lambda})\left[\bar{\lambda}(1-\bar{\lambda})-v_{\lambda}\right]}{\alpha\left[\bar{\lambda}^{2}(1-\bar{\lambda})-v_{\lambda}(1+\bar{\lambda})\right]}
$$

The expected weight $\bar{w}_{\Delta \pi}$ depends crucially on the degree of uncertainty. As shown in Figure2, larger values of $v_{\lambda}$ increase $\bar{w}_{\Delta \pi}$, given a mean of $\lambda$. In the following analysis, we set the upper limit of the variance $v_{\lambda}$ as $\bar{\lambda}^{2}(1-\bar{\lambda}) /(1+\bar{\lambda})$ in order to keep the expected weight $\bar{w}_{\Delta \pi}$ positive. $^{19}$

\subsection{Initial Policy Response}

Rational expectations equilibrium (REE) with optimal monetary policy is a triplet of stochastic processes for inflation, the output gap, and the interest rate, such that it is a bounded solution to the system consisting of IS curve (3), Phillips curve (7), and optimal policy plan (22), together with the central bank's expectations of the output gap and inflation based on (20) (21). Here, we conduct the simulation, assuming as in previous literature that $\bar{\lambda}$ is consistent with its true value $\lambda$, i.e. $\bar{\lambda}=\lambda$.

As the first step, we analyze the initial policy response to a natural rate of interest shock. The initial policy response can be given by the following parameter $a_{1}$ in the minimal-state-variable REE process of the nominal interest rate: ${ }^{20}$

\footnotetext{
${ }^{17}$ The beta distribution reduces to the uniform distribution over [0,1] if $a=b=1$.

${ }^{18}$ When the parameter $\lambda$ is formed with beta distribution, whose probability densities is (24), the mean of its inverse is $E[1 / \lambda]=(a+b-1) /(a-1)$. Then, substituting this mean into (19) and eliminating the parameters $a$ and $b$ by using $E[\lambda]=a /(a+b)$ and $V[\lambda]=a b /(a+b+1)(a+b)^{2}$, we obtain (25).

${ }^{19}$ In the case of $\bar{\lambda}=0.5$, where $v_{\lambda}$ reaches its upper limit (0.288), the beta distribution reduces to the uniform distribution.

${ }^{20}$ As McCallum $(1983,2003 \mathrm{a}, \mathrm{b})$ suggests, the minimal-state-variable (MSV) REE is the unique equilibrium of "well formulated" linear rational expectations models. Since our model satisfies requirements for the well formulated models, interest rate process (26) is unique, which justifies the comparison of interest rate processes under certainty equivalence and under uncertainty considered
} 


$$
i_{t}=a_{1} r_{t}^{n}+a_{2} \pi_{t-1}+a_{3} \pi_{t-2}+a_{4} x_{t-1}+a_{5} i_{t-1}+a_{6} i_{t-2} .
$$

We examine how the degree of uncertainty affects the initial policy response $a_{1}$ for a given $E_{t}^{C B}[\lambda] \equiv \bar{\lambda}$. Simulation result, shown in Figure 3, suggests that the initial policy response becomes more aggressive as the degree of uncertainty about $\lambda$ increases. That is, Brainard's conservatism principle does not hold: when the central bank faces parameter uncertainty, the optimal response coefficients are larger than under certainty equivalence, so optimal monetary policy is more aggressive. This is true for all values of $\bar{\lambda}$ and $w_{i}$.

In order to investigate the background of this result, we decompose the total effect of uncertainty on the initial policy response into two factors. One is the effect of uncertainty about loss function on the policy response; another is the effect of uncertainty about inflation dynamics on the policy response. To decompose the total effect into these two factors, we calculate the initial policy response with fixed weight in the social loss function, i.e. $w_{\Delta \pi}=(1-\bar{\lambda}) / \alpha \bar{\lambda}$. This presumption means that the central bank cares about the effect of the uncertainty about inflation dynamics, but ignores the effect of uncertainty about loss function in spite that the bank faces both uncertainties. Then, the difference between policy response under total uncertainty and policy response with fixed weight in the social loss function shows the effect of loss-function uncertainty. The difference between policy response with fixed weight in the social loss function and policy response under certainty equivalence shows the effect of uncertainty about inflation dynamics.

Since we obtain the same results regardless of values of $w_{i}$, we show only the result in the case of $w_{i}=0.236$. Figure 4 shows that both types of uncertainties, those about loss function and inflation dynamics, lead to a more aggressive policy response. The reason why loss-function uncertainty results in a more aggressive policy is because this uncertainty causes the increase in the expected weight on the variability of the change in inflation, as shown in Figure 2. The increase in this and determinate REE. 
expected weight does not generate any new tradeoffs between stabilization of the three target variables $\left(\pi_{t}, \Delta \pi_{t}, x_{t}\right)$, because price stability still achieves the minimum of their variances simultaneously. Therefore, the only effect of the increase in $\bar{w}_{\Delta \pi} \equiv E_{t}^{C B}\left[w_{\Delta \pi}\right]$ is to decrease the relative weight in interest rate stabilization. Then, it is desirable for the central bank to achieve price stability by responding more aggressively to shocks at the cost of the variability of the interest rate. The reason why uncertainty about inflation dynamics leads to a more aggressive policy is because such a policy can reduce uncertainty about the future development of target variables. As shown in equations (17) and (18), when the dynamics of inflation are uncertain, the conditional variances of inflation and output gap increase with the distance from target. Then, it pays to make sure current inflation is very stable by reacting more aggressively to shocks.

With a backward-looking model, Söderström (2002) finds that uncertainty about inflation dynamics leads the central bank to pursue a more aggressive monetary policy. We confirm his finding with a micro-founded forward-looking model. In addition, our analysis suggests that when the central bank faces uncertainty about inflation dynamics, it simultaneously faces loss-function uncertainty, and then it responds to shocks much more aggressively by placing much higher weight on price stability.

\subsection{Dynamic Policy Response}

The introduction of parameter uncertainty also has interesting implications for the dynamic response of monetary policy. Figures 5-6 show the impulse responses to a one standard deviation increase in the natural rate of interest, for $\bar{\lambda}=0.5$ and $\bar{\lambda}=0.25$ with $w_{i}=0.236$. As shown in the Figures, the optimal policy response of the nominal interest rate is very persistent, exploiting expectations for stabilization purposes as described by Woodford $(1999,2003)$ by inducing a long-lived sequence of expected negative output gap. The importance of such a highly inertial policy is remarkably invariant to the degree of uncertainty $v_{\lambda}$ as well as to changes in $\bar{\lambda}$ and $w_{i}$. (We do not report the figures for $\bar{\lambda}=0.75$ and $w_{i}=0.077$, since the main results do not change.) 
We can confirm more rigorously the desirability of highly inertial interest rate policy by investigating the optimal policy plan (22). As shown in Figure 7, as the mean of the parameter $\lambda$ decreases, the coefficients on the two lags of the interest rate in (22), i.e. $A_{2}$ and $A_{3}$, decrease while the coefficients on the lead-lag of the interest rate, i.e. $A_{1}$, increases. But, the sum of $A_{2}$ and $A_{3}$ are still high even when $\bar{\lambda}$ is very low, which implies that the inertial policy is desirable. Indeed, Amato and Laubach (2003) find, in the case of parameter certainty, that optimal policy plan (22) can be replicated by simple policy rule (23) with $A_{2}+A_{3}>1$ even when $\lambda$ is as low as 0.2 . In addition, what is very important is that, as shown in Appendix A, the coefficients on the two lags of the interest rate, $A_{2}$ and $A_{3}$, are invariant to the degree of uncertainty. That is, a highly inertial interest rate policy is desirable under parameter uncertainty.

This finding is completely opposite to that of Söderström (2002). With a backward-looking model, he finds that the central bank which faces uncertainty on inflation dynamics should return to a neutral stance soon after the bank initially responds to the shocks aggressively, since the strong initial move has neutralized a larger part of the shock. However, such a policy response is not desirable when private agents are forward-looking. If the central bank commits to initially responding to shocks aggressively but then returns to a neutral stance soon, the bank cannot stabilize the current output gap and thus inflation very much. Instead, by exploiting the expectations of the private sector and committing to the inertial policy, the central bank can stabilize the economy more effectively. Therefore, when the central bank faces parameter uncertainty, it is desirable for the bank to combine an aggressive policy response with a highly-inertial policy.

\subsection{Variance Frontier}

Finally, we show the expected social loss and the variance frontier. After taking the unconditional expectation of (12), the expected social loss becomes

$$
E(W)=V\left[\pi_{t}\right]+w_{x} V\left[x_{t}\right]+\bar{w}_{\Delta \pi} V\left[\Delta \pi_{t}\right]+w_{i} V\left[i_{t}\right],
$$

where the measure of variability for any variable $z$ is used here defined by 


$$
V[z] \equiv E\left[(1-\beta) \sum_{t=0}^{\infty} \beta^{t} E_{0} z_{t}^{2}\right]
$$

Except for discounting, this measure corresponds to the unconditional variance of $z_{t}$.

As shown in Figure 8, the weight on interest rate variability in the social loss function introduces a tradeoff between inflation and output gap variability on the one hand, and interest rate variability on the other. Since the central bank responds to a natural rate of interest shock more aggressively as the degree of uncertainty increases, this results in the lower variances of inflation and output gap and the higher variances of the interest rate. ${ }^{21}$ When the degree of uncertainty is very high, say, $v_{\lambda}$ reaches its upper limit $\bar{\lambda}^{2}(1-\bar{\lambda}) /(1+\bar{\lambda})$, the central bank tries to completely stabilize the output gap and inflation. This is because the expected weight that the bank should place on price stability becomes infinity. But, under such a highly uncertain situation, the central bank must pay the very high cost of the variability of the interest rate to stabilize the economy. As a result, as shown in Figure 9, in spite of the decrease in the variances of inflation and output gap, the expected social loss rises drastically as the degree of uncertainty approaches the upper limit.

\section{Alternative Models with Uncertainty about Inflation Dynamics}

In this section, we consider the robustness of our results to confirm that they do not depend on any specific model. In the previous sections, we used the hybrid Phillips curve (7), which is based on Galí and Gertler (1999) and Amato and Laubach (2003). Besides that model, however, there are alternatives to explain inflation inertia. For example, Steinsson (2003) proposes a more general specification of rule-of-thumb price setting than ours. Instead of (5), he assumes that rule-of-thumb agents set their prices to equal the geometric mean of the prices chosen in the previous period by both optimizing and rule-of-thumb price setters, adjusted for the previous period's output

\footnotetext{
${ }^{21}$ Figure 8 shows the result in the case of $w_{i}=0.236$. Although the variance of nominal interest rate increases in the case of $w_{i}=0.077$, the fundamental feature of the variance frontier remains same.
} 
gap as well as for the previous period's inflation rate. (In (5), rule-of-thumb price setters update their prices using only the previous inflation rate, but not the previous output gap.) The hybrid Phillips curve which Steinsson (2003) derives nests both the New Keynesian Phillips curve and the Old Keynesian Phillips curve as a particular case. The approach of Giannoni and Woodford (2003) is different from the rule-of-thumb approach. They assume, as in Christiano et al. (2001), that prices are not held constant between the dates at which they are re-optimized, but instead are automatically adjusted on the basis of the most recent quarter's increase in the aggregate price index, by a percentage that is a fraction of the percentage increase in the index. Then, Steinsson (2003) and Giannoni and Woodford (2003) respectively derive the social loss function based on a second-order approximation of the representative household's welfare in their models. (See Appendix B for the details.)

Although the forms of the hybrid Phillips curves and social loss functions differ in details among alternatives, there are two important common features, which are also held by our model in the previous sections. First, the weight of rule-of-thumb price setters (in the case of Steinsson) and the degree of indexation (in the case of Giannoni and Woodford) affect the degree of inflation persistence. Second, the weight of price stability in the social loss function is a non-linear function of the weight of rule-of-thumb price setters or the degree of indexation. In this setting, when the central bank is uncertain about the weight of rule-of-thumb agents or the degree of indexation, the bank faces both loss-function uncertainty and inflation-dynamics uncertainty. Then, as the degree of uncertainty increases, the expected weight of price stability in the loss function increases, and the conditional variances of the target variables increase. These lead the central bank to pursue a more aggressive monetary policy. Indeed, Figure 10 shows that, in both alternative models, the initial policy response to a natural rate of interest shock becomes more aggressive than under certainty equivalence. Although the degree of aggressiveness of policy response differs among alternatives, these results are clearly opposite to Brainard's common wisdom. ${ }^{22}$

\footnotetext{
${ }^{22}$ In the model of Giannoni and Woodford (2003), the degree of aggressiveness of policy response is fairly smaller than those of alternative models. This is because, in Giannoni and Woodford's model, the coefficient on the lagged inflation rate in the hybrid Phillips curve increases only up to $1 /(1+\beta)$ even in
} 
We can also confirm that, in the alternative models, a highly inertial interest rate policy is desirable under uncertainty. As shown in Appendix B, the coefficients on the two lags of the interest rate in each optimal policy plan are invariant to the degree of uncertainty. In addition, these coefficients are very high even when the weight of rule-of-thumb price setters or the degree of indexation is high.

\section{The Effect of Uncertainty about Output Dynamics on Optimal Policy}

Finally, in this section, we apply our Bayesian approach to the case of uncertainty about the output dynamics. Söderström (2002) finds, with a backward-looking model, that the central bank should respond to shocks less aggressively when the bank is uncertain about output dynamics. We examine whether his finding holds in a forward-looking model or not. We use a modified IS curve which nests the purely forward-looking IS curve (3) as a particular case, and allows for a fraction of consumers that follow a rule of thumb to decide their spending. Assuming that central bank is uncertain about the weight of rule-of-thumb consumers, we examine the effect of uncertainty on optimal monetary policy.

\subsection{IS curve and Loss Function with Rule-of-Thumb Consumers}

Following Amato and Laubach (2003), we assume that at the beginning of each period, each household learns whether it is able to choose consumption optimally, or whether instead it chooses consumption based on a simple rule of thumb. Let $\psi$ denote the

the case of full indexation. On the other hand, in the hybrid Phillips curve of Steinsson (2003) and ours, the coefficient on the lagged inflation rate converges to 1 as the weight of rule-of-thumb agents increases. (See Appendix B1.) This implies that the model of Giannoni and Woodford nests only more limited types of Phillips curve than that of Steinsson and ours. Therefore, even when the degree of uncertainty about indexation increases up to the upper limit, the central bank does not face a highly serious uncertainty about inflation dynamics and loss function. However, taking into account the fact that the empirical results of the hybrid Phillips curve varies with studies very significantly, as discussed in section 3.1., Giannoni and Woodford's model does not seem to describe well enough the degree of uncertainty which the central bank faces in the real world. 
probability that a household is able to optimize, which is independent of the household's history. Thus, by the law of large numbers, in each period a fraction $\psi$ of households choose consumption optimally. Since financial markets are assumed to be complete so that risks are efficiently shared, all households that have the opportunity to choose consumption optimally make the same choice, which we denote by $C_{t}^{o}$. The remaining fraction $1-\psi$ chooses its consumption in period $t, C_{t}^{r}$, following the simple rule of thumb

$$
C_{t}^{r}=C_{t-1}
$$

Here, $C_{t}$ is aggregate per capita consumption in period $t$, which is given by $C_{t} \equiv \psi C_{t}^{o}+(1-\psi) C_{t}^{r}$.

In this setting, combining the first-order condition characterizing the optimal choice $C_{t}^{o}$ with the goods market clearing condition, Amato and Laubach (2003) derives the following IS equation.

$$
\begin{gathered}
x_{t}=(1-\delta) x_{t-1}+\delta E_{t}\left[x_{t+1}\right]-\widetilde{\sigma}^{-1}\left(i_{t}-E_{t}\left[\pi_{t+1}\right]-r_{t}^{n}\right), \\
\text { where } r_{t}^{n} \equiv \widetilde{\sigma} E_{t}\left[\delta y_{t+1}^{n}+(1-\delta) y_{t-1}^{n}-y_{t}^{n}-\left(\widetilde{g}_{t+1}-\widetilde{g}_{t}\right)\right] .
\end{gathered}
$$

The parameter $\psi$ enters (30) and (31) through the following relationships.

$$
\delta \equiv \frac{1}{2-\psi}, \quad \widetilde{\sigma}^{-1} \equiv \frac{\psi}{2-\psi} \sigma^{-1}, \quad \widetilde{g}_{t} \equiv \frac{\psi}{2-\psi} g_{t} .
$$

In the case where all households are able to choose optimally, i.e. $\psi=1$, (30) reduces to the standard intertemporal IS equation (3). Changes in $\psi$ affect several elements of the model. First, smaller values of $\psi$ increase the degree of endogenous persistence in the output gap, as captured by $\delta$ converging to 0.5 from above as $\psi$ goes to 0 . Second, smaller values of $\psi$ dampen the impact of gaps between the real and natural interest rates on the output gap, as captured by $\tilde{\sigma}^{-1}$ converging to 0 from above as $\psi$ goes to 0 . Third, smaller values of $\psi$ reduce the effect of disturbance $g_{t}$ (through the natural rate of interest) on current output.

Then, following Amato and Laubach (2003) and Woodford (2003), we derive a second-order Taylor series approximation to the representative household's welfare in the presence of rule-of-thumb agents (but absent rule-of-thumb price setters). 
Specifically, social welfare can be expressed in the form of a loss function

$$
\begin{gathered}
W=E_{0} \sum_{t=0}^{\infty} \beta^{t}\left[\pi_{t}^{2}+w_{x} x_{t}^{2}+w_{\Delta y}\left(y_{t}-y_{t-1}\right)^{2}+w_{i} i_{t}^{2}\right], \\
\text { where } w_{x} \equiv \frac{\kappa}{\theta}, \quad w_{\Delta y} \equiv \frac{\sigma}{\sigma+\omega} \frac{1-\psi}{\psi} w_{x} .
\end{gathered}
$$

Since a fraction 1- $\psi$ of households is choosing consumption following the rule of thumb (29), fluctuations in output (not only in the output gap) create welfare losses. As $\psi$ declines, such losses increase through an increase in the weight $w_{\Delta y}$, which is a non-linear function of $\psi$. As discussed in the section 2.3., the presence of the interest rate in the loss function results from transactions frictions and the non-negativity constraint of nominal interest rates.

\subsection{Optimal Monetary Policy under Uncertainty about Rule-of-Thumb Consumers}

Here, we assume that the central bank knows the structure of the economy, the natural rate of output $y_{t}^{n}$, the marginal utility of consumption shock $g_{t}$, and all the structural deep parameters except $\psi$. Since the information on the parameter $\psi$ is not included in the central bank's information set $\Omega_{t}^{C B}$, i.e. $\psi \notin \Omega_{t}^{C B}$, neither is the following information.

$$
\begin{aligned}
\delta \equiv \frac{1}{2-\psi} \notin \Omega_{t}^{C B}, \quad \widetilde{\sigma}^{-1} \equiv \frac{\psi}{2-\psi} \sigma^{-1} \notin \Omega_{t}^{C B}, \quad \widetilde{g}_{t} \equiv \frac{\psi}{2-\psi} g_{t} \notin \Omega_{t}^{C B}, \\
w_{\Delta y} \equiv \frac{\sigma}{\sigma+\omega} \frac{1-\psi}{\psi} w_{x} \notin \Omega_{t}^{C B} .
\end{aligned}
$$

That is, when the central bank is uncertain about what fraction of consumers follow a rule of thumb, the bank faces two different types of uncertainty: 1) uncertainty about output dynamics (34); 2) uncertainty about the social welfare function (35). Since both uncertainties are correlated with each other through the unknown parameter $\psi$, the central bank takes into account the cross-parameter restrictions between different types of uncertainty. Under these uncertainties, the central bank conducts optimal policy with its own information set $\Omega_{t}^{C B}$ and the following prior belief: 


$$
E_{t}^{C B}[\psi] \equiv E\left[\psi \mid \Omega_{t}^{C B}\right] \equiv \bar{\psi}, V_{t}^{C B}[\psi] \equiv V\left[\psi \mid \Omega_{t}^{C B}\right] \equiv v_{\psi} .
$$

See Appendix C for the details of optimal policy plan.

Here, again, we assume that the central bank's prior belief on the parameter $\psi$ is formed with beta distribution. Using the same calibrated parameters as those in the section 4.1, we analyze the initial policy response to a marginal utility of consumption shock $g_{t}$. We assume that the process of $g_{t}$ follows a stationary first-order autoregressive process, $g_{t}=\rho_{g} g_{t-1}+\varepsilon_{t}$, where $\rho_{g}=0.35$ and $\varepsilon_{t}$ is i.i.d. means zero disturbance with standard deviation of 8.34. This specification is equal to Amato and Laubach (2003). Fixing $\lambda$ at 1 in the Phillips curve (7), that is, assuming that all price setters are optimizing, we report results for $\bar{\psi}=0.75,0.5,0.25$. We conduct the simulation, assuming as in previous literature that $\bar{\psi}$ is consistent with its true value $\psi$, i.e. $\bar{\psi}=\psi$.

The simulation result, shown in Figure 11, suggests that the initial policy response becomes more aggressive as the degree of uncertainty about $\psi$ increases. That is, Brainard's conservatism principle does not hold in the case of uncertainty about aggregate demand structure, either. This is true for all values of $\bar{\psi}$ and $w_{i}$.

There are three reasons for this result. First is the effect of uncertainty about loss function; second is the effect of uncertainty about output dynamics; third is the effect of the positive correlation between policy multiplier and transmission of natural rate of interest shock. The first two reasons are the same as in the case of uncertainty about rule-of-thumb price setters. Loss-function uncertainty results in a more aggressive policy, because this uncertainty causes the increase in the expected weight on the variability of the change in output, i.e. $E_{t}^{C B}\left[w_{\Delta y}\right]$, and hence relatively reduces the weight on the variability of interest rate $w_{i}{ }^{23}$ The reason why uncertainty about output dynamics leads to a more aggressive policy is because such a policy can reduce

${ }^{23}$ When the central bank's prior belief on the parameter $\psi$ is formed with a beta distribution, the expected weight on the variability of the change in output is given by

$$
\bar{w}_{\Delta y} \equiv E_{t}^{C B}\left[w_{\Delta y}\right]=\frac{\sigma w_{x}}{\sigma+\omega}\left(E_{t}^{C B}\left[\frac{1}{\psi}\right]-1\right)=\frac{\sigma w_{x}}{\sigma+\omega} \frac{(1-\bar{\psi})\left[\bar{\psi}(1-\bar{\psi})-v_{\psi}\right]}{\left[\bar{\psi}^{2}(1-\bar{\psi})-v_{\psi}(1+\bar{\psi})\right]} .
$$

As the degree of uncertainty $v_{\psi}$ increases, the central bank should place higher weight on the variability of the change in output. 
uncertainty about the future development of target variables. As shown in Appendix C, when the dynamics of output are uncertain, the conditional variance of output (gap) increases with the distances from its target. Then, it pays to make sure current output is very stable by reacting more aggressively to shocks.

The positive correlation between policy multiplier and the transmission of natural rate of interest shock is an additional factor that results in a more aggressive policy response. Here, the policy multiplier measures the effect of policy on the output gap, and is given by the coefficient of the forth term on the right-hand side of the following rearranged IS curve.

$$
x_{t}=(1-\delta) x_{t-1}+\delta E_{t}\left[x_{t+1}\right]+\tilde{\sigma}^{-1} r_{t}^{n}-\tilde{\sigma}^{-1}\left(i_{t}-E_{t}\left[\pi_{t+1}\right]\right)
$$

The transmission of natural rate of interest shock measures the effect of its shock on the output gap, and is given by the coefficient of the third term on the right-hand side. Since, both the policy multiplier and the transmission of shock depend on the parameter $\tilde{\sigma}^{-1} \notin \Omega_{t}^{C B}$, they are positively correlated by definition. ${ }^{24}$ To gain insight into the reason why the positive correlation between them results in a more aggressive policy response, consider the simple static problem of minimizing the expected square value of variable $Y=\zeta X-m C$, where $X$ is a stochastic shock, $C$ is the control variable, $\zeta$ is the transmission of shock, and $m$ is the policy multiplier. When the central bank can observe $X$ but faces uncertainty about $\zeta$ and $m$, the optimal control is given by

$$
C^{*}=\left(\frac{E[m] E[\zeta]+\operatorname{Cov}[\zeta, m]}{(E[m])^{2}+V[m]}\right) X .
$$

Note that in the absence of uncertainty, the optimal policy is $C^{*}=(\zeta / m) X$. Parameter uncertainty leads to the classical attenuation result when the covariance between the policy multiplier and the transmission of shock is zero, that is, $\operatorname{Cov}[\zeta, m]=0$. When

${ }^{24}$ The positive correlation between them results from the existence of rule-of-thumb consumers. Because the rule-of-thumb consumers set their spending as the previous aggregate per capita consumption, and respond to neither the interest rate nor preference shock in the current period, the increase in the weight of rule-of-thumb consumers leads to the decline in both the policy multiplier and the transmission of shock. This can be confirmed by rearranging (37) as follows:

$$
y_{t}=\frac{1-\psi}{2-\psi} y_{t-1}+\frac{1}{2-\psi} E_{t}\left[y_{t+1}\right]-\frac{\psi}{(2-\psi) \sigma}\left(i_{t}-E_{t}\left[\pi_{t+1}\right]\right)+\frac{\psi\left(1-\rho_{g}\right)}{(2-\psi)} g_{t},
$$

where $\rho_{g}$ is the serial correlation in the marginal utility of consumption shock $g_{t}$. 
$\operatorname{Cov}[\zeta, m]>0$, however, this leads to a less-attenuation or a more aggressive policy response than that with certainty.

In order to examine how the above three effects contribute to the aggressive policy response, we decompose the initial policy response into three factors. Figure 12 shows the result. (Since the main results do not change regardless of values of $\bar{\psi}$ and $w_{i}$, we show only the result in the case of $\bar{\psi}=0.5$ and $w_{i}=0.236$.) The bold line shows the initial policy response under total uncertainty. The solid (thin) line shows the policy response under uncertainty with the fixed weight of loss function, i.e. $w_{\Delta y}=\sigma(1-\bar{\psi}) w_{x} /(\sigma+\omega) \bar{\psi}$. This presumption implies that the central bank ignores the effect of loss-function uncertainty. The dashed line shows the policy response under uncertainty with the fixed weight of loss function and the fixed transmission of shock. $^{25}$ This means that the policy multiplier is independent of the transmission of shock and that the central bank cares only about the effect of output-dynamics uncertainty. Then, the difference (A) in Figure 12 shows the effect of uncertainty about loss function, and the difference (B) shows the effect of the positive correlation between policy multiplier and transmission of shock. The difference (C) shows the effect of uncertainty about output dynamics. As clearly shown in Figure 12, all three effects result in a more aggressive policy response than under certainty equivalence.

Our finding is opposite to that of Söderström (2002), who finds, with a backward-looking model, that the central bank should respond to shocks less aggressively when the bank faces uncertainty about the IS curve. The reason for the difference between our finding and that of Söderström results mainly from our consideration about loss-function uncertainty and the positive correlation between policy multiplier and transmission of shock, which are suggested by the micro-foundation of the model. Söderström does not take into account these two points in his analysis.

\footnotetext{
${ }^{25}$ In this calculation, we assume that the central bank is certain about the transmission of shock, i.e., $\psi\left(1-\rho_{g}\right) /(2-\psi)$ in the rearranged IS curve shown in footnote 24 , but uncertain about the coefficients of the other three terms on the right hand side.
} 


\section{Conclusion}

This paper has examined the implication of optimal monetary policy under parameter uncertainty in a micro-founded forward-looking model. The result of our analysis is completely opposite to Brainard's common wisdom, which seemed to capture the way actual policy makers viewed their decisions (Blinder 1998). Our analysis suggests that when the central bank is uncertain about inflation-dynamics, the bank should take into account the loss-function uncertainty and respond more aggressively to shocks by placing much higher weight on price stability. Such an aggressive policy response also can be justified by an action necessary to reduce uncertainty about the future development of target variables. We also confirmed that when the central bank faces parameter uncertainty, it is desirable for the bank to combine an aggressive policy response with a highly-inertial policy. As first shown in Rotemberg and Woodford (1999) and Woodford (1999), a highly inertial interest rate policy allows the central bank to affect the private sector's expectations appropriately. We showed that such an inertial policy is desirable under parameter uncertainty.

In practice, in addition to the uncertainty about the structure of aggregate supply (inflation dynamics), central banks also face uncertainty about the structure of aggregate demand. That is, they are uncertain about the degree of output persistence, policy multiplier, and transmission of demand shocks. Then, again, the central bank should take into account the loss-function uncertainty, because the weights of a social loss function are directly related to unknown deep-parameters with regard to aggregate demand. We found that uncertainty about the structure of aggregate demand also leads to a more aggressive policy response, which can be justified not only by the effect of loss-function uncertainty, but also by the possible positive correlation between policy multiplier and transmission of shocks.

The difference between our results and those of previous literature which confirms Brainard's conservatism principle results mainly from our consideration about the cross-parameter restrictions between different types of uncertainties. That is, cross-parameter restrictions between uncertainty about loss function and uncertainty 
about the structural equations, and those between policy multiplier and transmission of shocks. These cross-parameter restrictions, which are based on the micro-foundation of the models, have been largely ignored in most previous literature. Our results suggest that accounting for them is critical for investigating the effect of uncertainty on optimal monetary policy. Although further work is required to determine the robustness of the model, we believe that the insights we pointed out deserve attention in discussions of practical policy conduct. 


\section{Appendix A. Optimal Plan under Uncertainty on Rule-of-Thumb Price Setters}

The objective of the central bank is to minimize (16) with respect to the endogenous variables subject to conditional variances (17)(18) and constraints (20)(21). The associated Lagrangian then takes the form

$$
E_{0}^{C B}\left[\begin{array}{l}
\pi_{0}^{2}+w_{x} x_{0}^{2}+\bar{w}_{\Delta \pi}\left(\pi_{0}-\pi_{-1}\right)^{2}+w_{i} i_{0}^{2} \\
+v_{\lambda} \beta^{-1}\left(1+\bar{w}_{\Delta \pi}+w_{x} \sigma^{-2}\right)\left\{\left(\alpha^{-1}-1+\beta\right) \pi_{0}-\alpha^{-1} \pi_{-1}+\kappa x_{0}\right\}^{2} \\
+\sum_{t=1}^{\infty} \beta^{t}\left[\begin{array}{l}
\left(E_{t-1}^{C B}\left[\pi_{t}\right]\right)^{2}+w_{x}\left(E_{t-1}^{C B}\left[x_{t}\right]\right)^{2}+\bar{w}_{\Delta \pi}\left(E_{t-1}^{C B}\left[\pi_{t}-\pi_{t-1}\right]\right)^{2}+w_{i} i_{t}^{2} \\
+v_{\lambda} \beta^{-1}\left(1+\bar{w}_{\Delta \pi}+w_{x} \sigma^{-2}\right)\left\{\left(\alpha^{-1}-1+\beta\right) \pi_{t}-\alpha^{-1} \pi_{t-1}+\kappa x_{t}\right\}^{2}
\end{array}\right] \\
+2 \sum_{t=0}^{\infty} \beta^{t}\left[\phi_{x, t}\left\{x_{t}-x_{t+1}+\sigma^{-1}\left(i_{t}-\pi_{t+1}\right)\right\}+\phi_{\pi, t}\left(\pi_{t}-\bar{\gamma}_{b} \pi_{t-1}-\bar{\gamma}_{f} \pi_{t+1}-\bar{\gamma}_{\kappa} \kappa x_{t}\right)\right]
\end{array}\right],
$$

where $\phi_{x, t}$ and $\phi_{\pi, t}$ are Lagrange multipliers on (20)(21) in period $t$, respectively. The first-order conditions with respect to $\pi_{t}, x_{t}$, and $i_{t}$ are, in every period $t \geq 0$,

$$
\begin{aligned}
& \pi_{t}+\bar{w}_{\Delta \pi}\left(\pi_{t}-\pi_{t-1}\right)-\beta \bar{w}_{\Delta \pi}\left(E_{t}^{C B}\left[\pi_{t+1}\right]-\pi_{t}\right)+\phi_{\pi, t}-\bar{\gamma}_{f} \beta^{-1} \phi_{\pi, t-1}-\beta \bar{\gamma}_{b} E_{t}^{C B}\left[\phi_{\pi, t+1}\right] \\
& \quad-\beta^{-1} \sigma^{-1} \phi_{x, t-1}+v_{\lambda} \beta^{-1}\left(1+\bar{w}_{\Delta \pi}+w_{x} \sigma^{-2}\right)\left(\alpha^{-1}-1+\beta\right)\left\{\left(\alpha^{-1}-1+\beta\right) \pi_{t}-\alpha^{-1} \pi_{t-1}+\kappa x_{t}\right\} \\
& \quad-v_{\lambda} \alpha^{-1}\left(1+\bar{w}_{\Delta \pi}+w_{x} \sigma^{-2}\right)\left\{\left(\alpha^{-1}-1+\beta\right) E_{t}^{C B}\left[\pi_{t+1}\right]-\alpha^{-1} \pi_{t}+\kappa E_{t}^{C B}\left[x_{t+1}\right]\right\}=0, \\
& w_{x} x_{t}-\bar{\gamma}_{\kappa} \kappa \phi_{\pi, t}+\phi_{x, t}-\beta^{-1} \phi_{x, t-1} \\
& \quad+v_{\lambda} \kappa \beta^{-1}\left(1+\bar{\lambda}_{\Delta \pi}+\lambda_{x} \sigma^{-2}\right)\left\{\left(\alpha^{-1}-1+\beta\right) \pi_{t}-\alpha^{-1} \pi_{t-1}+\kappa x_{t}\right\}=0, \\
& w_{i} i_{t}+\sigma^{-1} \phi_{x, t}=0,
\end{aligned}
$$

together with initial conditions $\phi_{x,-1}=\phi_{\pi,-1}=0$. Combining the first-order conditions (A2) (A3)(A4) to eliminate all Lagrange multipliers yields optimal policy plan (22), where the coefficients are as follows.

$$
\begin{aligned}
& A_{1} \equiv \beta \bar{\gamma}_{b}\left(1+\bar{\gamma}_{b}\right)^{-1}, \quad A_{2} \equiv \beta^{-1}\left(1+\bar{\gamma}_{f}+\bar{\gamma}_{\kappa} \kappa \sigma^{-1}\right)\left(1+\bar{\gamma}_{b}\right)^{-1}, \quad A_{3} \equiv-\bar{\gamma}_{f} \beta^{-2}\left(1+\bar{\gamma}_{b}\right)^{-1}, \\
& A_{4} \equiv-\bar{\gamma}_{\kappa} \kappa \sigma^{-1} w_{i}^{-1}\left(1+\bar{\gamma}_{b}\right)^{-1}\left\{\beta \bar{w}_{\Delta \pi}+v_{\lambda}\left(1+\bar{w}_{\Delta \pi}+w_{x} \sigma^{-2}\right)\left(\alpha^{-1}+\bar{\gamma}_{b} \bar{\gamma}_{\kappa}^{-1}\right)\left(\alpha^{-1}-1+\beta\right)\right\}, \\
& A_{5} \equiv \bar{\gamma}_{\kappa} \kappa \sigma^{-1} w_{i}^{-1}\left(1+\bar{\gamma}_{b}\right)^{-1}\left[1+(1+\beta) \bar{w}_{\Delta \pi}+v_{\lambda} \beta^{-1}\left(1+\bar{w}_{\Delta \pi}+w_{x} \sigma^{-2}\right)\right. \\
& \left.\times\left\{\beta\left(\alpha^{-2}+\beta\right)+\left(\alpha^{-1}-1+2 \beta\right)\left(\alpha^{-1}-1\right)+\left(\alpha^{-1}-1+\beta\right) \bar{\gamma}_{\kappa}^{-1}+\beta \bar{\gamma}_{b} \alpha^{-1} \bar{\gamma}_{k}^{-1}\right\}\right], \\
& A_{6} \equiv-\bar{\gamma}_{\kappa} \kappa \sigma^{-1} w_{i}^{-1}\left(1+\bar{\gamma}_{b}\right)^{-1}\left[\bar{w}_{\Delta \pi}+v_{\lambda} \beta^{-1}\left(1+\bar{w}_{\Delta \pi}+w_{x} \sigma^{-2}\right)\left\{\alpha^{-1} \bar{\gamma}_{\kappa}^{-1}+\left(\alpha^{-1}+\bar{\gamma}_{f} \beta^{-1} \bar{\gamma}_{\kappa}^{-1}\right)\left(\alpha^{-1}-1+\beta\right)\right\}\right] \text {, } \\
& A_{7} \equiv v_{\lambda} \kappa \bar{\gamma}_{f} \alpha^{-1} \beta^{-2} \sigma^{-1} w_{i}^{-1}\left(1+\bar{w}_{\Delta \pi}+w_{x} \sigma^{-2}\right)\left(1+\bar{\gamma}_{b}\right)^{-1} \\
& A_{8} \equiv-\bar{\gamma}_{b} \sigma^{-1} w_{i}^{-1}\left(1+\bar{\gamma}_{b}\right)^{-1}\left\{\beta w_{x}+v_{\lambda} \kappa^{2}\left(1+\bar{w}_{\Delta \pi}+w_{x} \sigma^{-2}\right)\left(1+\bar{\gamma}_{\kappa} \alpha^{-1} \bar{\gamma}_{b}^{-1}\right)\right\}, \\
& A_{9} \equiv \sigma^{-1} w_{i}^{-1}\left(1+\bar{\gamma}_{b}\right)^{-1}\left[w_{x}+v_{\lambda} \kappa^{2} \beta^{-1}\left(1+\bar{w}_{\Delta \pi}+w_{x} \sigma^{-2}\right)\left\{1+\bar{\gamma}_{\kappa}\left(\alpha^{-1}-1+\beta\right)\right\}\right] \text {, } \\
& A_{10} \equiv-\bar{\gamma}_{f} \beta^{-1} \sigma^{-1} w_{i}^{-1}\left(1+\bar{\gamma}_{b}\right)^{-1}\left\{w_{x}+v_{\lambda} \kappa^{2} \beta^{-1}\left(1+\bar{w}_{\Delta \pi}+w_{x} \sigma^{-2}\right)\right\} \text {. }
\end{aligned}
$$




\section{Appendix B. Alternative Models with Inflation Inertia}

\section{B1. Steinsson (2003) model}

Instead of (5), Steinsson assumes that rule-of-thumb agents set their prices according to the following rule:

$$
p_{t}^{r}=P_{t-1}^{*} \frac{P_{t-1}}{P_{t-2}}\left(\frac{Y_{t-1}}{Y_{t-1}^{n}}\right)^{\delta} .
$$

When $\delta=0$, this rule nests (5) as a special case. Phillips curve is then given by

$$
\begin{gathered}
\pi_{t}=\gamma_{b} \pi_{t-1}+\gamma_{f} E_{t}^{C B}\left[\pi_{t+1}\right]+\kappa_{c} x_{t}+\kappa_{b} x_{t-1}, \\
\text { where } \kappa_{c} \equiv \gamma_{\kappa} \kappa-\alpha \beta \kappa_{b}, \quad \kappa_{b} \equiv \frac{\delta(1-\alpha)(1-\lambda)}{\alpha+(1-\lambda)\{1-\alpha(1-\beta)\}},
\end{gathered}
$$

and the other coefficients are the same as those in our model. In the case that all price setters are optimizing, i.e. $\lambda=1$, (B2) reduces to the New Keynesian Phillips Curve (11). On the other hand, taking the limit as $\lambda \rightarrow 0$, (B2) becomes

$$
\pi_{t}=\frac{1}{1+\alpha \beta} \pi_{t-1}+\frac{\alpha \beta}{1+\alpha \beta} E_{t}\left[\pi_{t+1}\right]-\frac{\alpha \beta(1-\alpha)}{1+\alpha \beta} x_{t}+\frac{\delta(1-\alpha)}{1+\alpha \beta} x_{t-1} .
$$

The unique bounded solution of (B3) is

$$
\pi_{t}=\pi_{t-1}+\delta(1-\alpha) x_{t-1},
$$

which is the so-called "Old Keynesian" Phillips curve.

In Steinsson's model, the social loss function is given by

$$
E_{0}\left[\sum_{t=0}^{\infty} \beta^{t}\left\{\pi_{t}^{2}+w_{x} x_{t}^{2}+w_{\Delta \pi}\left(\pi_{t}-\pi_{t-1}+w_{l x} x_{t-1}\right)^{2}+w_{i} i_{t}^{2}\right\}\right] \text {, where } w_{l x} \equiv \delta(1-\alpha) .
$$

Taking expectations of the loss function (B5) conditional on the central bank's information set $\Omega_{0}^{C B}$ leads to

$$
E_{0}^{C B}\left[\begin{array}{l}
\pi_{0}^{2}+w_{x} x_{0}^{2}+\bar{w}_{\Delta \pi}\left(\pi_{0}-\pi_{-1}+w_{l x} x_{-1}\right)^{2}+w_{i} i_{0}^{2}+\beta\left\{\left(1+\bar{w}_{\Delta \pi}\right) V_{0}^{C B}\left[\pi_{1}\right]+w_{x} V_{0}^{C B}\left[x_{1}\right]\right\} \\
+\sum_{t=1}^{\infty} \beta^{t}\left[\begin{array}{l}
\left(E_{t-1}^{C B}\left[\pi_{t}\right]\right)^{2}+w_{x}\left(E_{t-1}^{C B}\left[x_{t}\right]\right)^{2}+\bar{w}_{\Delta \pi}\left(E_{t-1}^{C B}\left[\pi_{t}-\pi_{t-1}+w_{l x} x_{t-1}\right]\right)^{2}+w_{i} i_{t}^{2} \\
+\beta\left\{\left(1+\bar{w}_{\Delta \pi}\right) V_{t}^{C B}\left[\pi_{t+1}\right]+w_{x} V_{t}^{C B}\left[x_{t+1}\right]\right\}
\end{array}\right] .
\end{array}\right] .
$$

From IS curve (3) and Phillips curve (B2), it follows that the conditional variance of the output gap takes the same form as (18) and that of inflation is given by

$$
V_{t}^{C B}\left[\pi_{t+1}\right]=v_{\lambda} \beta^{-2}\left[\left(\alpha^{-1}-1+\beta\right) \pi_{t}-\alpha^{-1} \pi_{t-1}+\{\kappa+\beta \delta(1-\alpha)\} x_{t}-\delta \alpha^{-1}(1-\alpha) x_{t-1}\right]^{2}+\text { t.i.p. }
$$

The objective of the central bank is to minimize (B6) with respect to the endogenous variables subject to conditional variances (18)(B7), constraint (20), and the following 
constraint (B8).

$$
\pi_{t}=\bar{\gamma}_{b} \pi_{t-1}+\bar{\gamma}_{f} E_{t}^{C B}\left[\pi_{t+1}\right]+\bar{\kappa}_{c} x_{t}+\bar{\kappa}_{b} x_{t-1}
$$

$$
\text { where } \bar{\kappa}_{c} \equiv \bar{\gamma}_{\kappa} \kappa-\alpha \beta \bar{\kappa}_{b}, \bar{\kappa}_{b} \equiv \frac{\delta(1-\alpha)(1-\bar{\lambda})}{\alpha+(1-\bar{\lambda})\{1-\alpha(1-\beta)\}} \text {, }
$$

and the other coefficients are the same as those in our model. The associated Lagrangian is given by

$$
E_{0}^{C B}\left[\begin{array}{l}
\pi_{0}^{2}+w_{x} x_{0}^{2}+\bar{w}_{\Delta \pi}\left(\pi_{0}-\pi_{-1}+w_{l x} x_{t-1}\right)^{2}+w_{i} i_{0}^{2} \\
+v_{\lambda} \beta^{-1}\left(1+\bar{w}_{\Delta \pi}+w_{x} \sigma^{-2}\right)\left\{\begin{array}{l}
\left(\alpha^{-1}-1+\beta\right) \pi_{0}-\alpha^{-1} \pi_{-1} \\
+\{\kappa+\beta \delta(1-\alpha)\} x_{0}-\delta \alpha^{-1}(1-\alpha) x_{-1}
\end{array}\right\} \\
+\sum_{t=1}^{\infty} \beta^{t}\left[\begin{array}{l}
\left(E_{t-1}^{C B}\left[\pi_{t}\right]\right)^{2}+w_{x}\left(E_{t-1}^{C B}\left[x_{t}\right]\right)^{2}+\bar{w}_{\Delta \pi}\left(E_{t-1}^{C B}\left[\pi_{t}-\pi_{t-1}+w_{l x} x_{t-1}\right]\right)^{2}+w_{i} i_{t}^{2} \\
+v_{\lambda} \beta^{-1}\left(1+\bar{w}_{\Delta \pi}+w_{x} \sigma^{-2}\right)\left\{\begin{array}{l}
\left(\alpha^{-1}-1+\beta\right) \pi_{t}-\alpha^{-1} \pi_{t-1} \\
+\{\kappa+\beta \delta(1-\alpha)\} x_{t}-\delta \alpha^{-1}(1-\alpha) x_{t-1}
\end{array}\right.
\end{array}\right\}^{2}
\end{array}\right],
$$

where $\phi_{x, t}$ and $\phi_{\pi, t}$ are Lagrange multipliers on (20)(B8) in period $t$, respectively. The first-order conditions with respect to $\pi_{t}, x_{t}$, and $i_{t}$ are, in every period $t \geq 0$,

$$
\begin{aligned}
& \pi_{t}+\bar{w}_{\Delta \pi}\left(\pi_{t}-\pi_{t-1}+w_{l x} x_{t-1}\right)-\beta \bar{w}_{\Delta \pi}\left(E_{t}^{C B}\left[\pi_{t+1}\right]-\pi_{t}+w_{l x} x_{t}\right) \\
& +\phi_{\pi, t}-\beta \bar{\gamma}_{b} E_{t}^{C B}\left[\phi_{\pi, t+1}\right]-\bar{\gamma}_{f} \beta^{-1} \phi_{\pi, t-1}-\sigma^{-1} \beta^{-1} \phi_{x, t-1} \\
& +v_{\lambda} \beta^{-1}\left(1+\bar{w}_{\Delta \pi}+w_{x} \sigma^{-2}\right)\left(\alpha^{-1}-1+\beta\right)\left[\begin{array}{l}
\left(\alpha^{-1}-1+\beta\right) \pi_{t}-\alpha^{-1} \pi_{t-1} \\
+\{\kappa+\beta \delta(1-\alpha)\} x_{t}-\delta \alpha^{-1}(1-\alpha) x_{t-1}
\end{array}\right] \\
& -v_{\lambda} \alpha^{-1}\left(1+\bar{w}_{\Delta \pi}+w_{x} \sigma^{-2}\right)\left[\begin{array}{l}
\left(\alpha^{-1}-1+\beta\right) E_{t}^{C B}\left[\pi_{t+1}\right]-\alpha^{-1} \pi_{t} \\
+\{\kappa+\beta \delta(1-\alpha)\} E_{t}^{C B}\left[x_{t+1}\right]-\delta \alpha^{-1}(1-\alpha) x_{t}
\end{array}\right]=0, \\
& w_{x} x_{t}+\beta \bar{w}_{\Delta \pi} w_{l x}\left(E_{t}^{C B}\left[\pi_{t+1}\right]-\pi_{t}+w_{l x} x_{t}\right)-\bar{\kappa}_{c} \phi_{\pi, t}-\beta \bar{\kappa}_{b} E_{t}^{C B}\left[\phi_{\pi, t+1}\right]+\phi_{x, t}-\beta^{-1} \phi_{x, t-1} \\
& +v_{\lambda}\left\{\kappa \beta^{-1}+\delta(1-\alpha)\right\}\left(1+\bar{w}_{\Delta \pi}+w_{x} \sigma^{-2}\right)\left[\begin{array}{l}
\left(\alpha^{-1}-1+\beta\right) \pi_{t}-\alpha^{-1} \pi_{t-1} \\
+\{\kappa+\beta \delta(1-\alpha)\} x_{t}-\delta \alpha^{-1}(1-\alpha) x_{t-1}
\end{array}\right] \\
& -v_{\lambda} \delta \alpha^{-1}(1-\alpha)\left(1+\bar{w}_{\Delta \pi}+w_{x} \sigma^{-2}\right)\left[\begin{array}{l}
\left(\alpha^{-1}-1+\beta\right) E_{t}^{C B}\left[\pi_{t+1}\right]-\alpha^{-1} \pi_{t} \\
+\{\kappa+\beta \delta(1-\alpha)\} E_{t}^{C B}\left[x_{t+1}\right]-\delta \alpha^{-1}(1-\alpha) x_{t}
\end{array}\right]=0, \\
& w_{i} i_{t}+\sigma^{-1} \phi_{x, t}=0,
\end{aligned}
$$

together with initial conditions $\phi_{x,-1}=\phi_{\pi,-1}=0$. Combining the conditions (B10)(B11) (B12) to eliminate all multipliers yields the law of motion for the interest rate implicit in the optimal plan. The interest rate rule which would implement the optimal plan takes the form 


$$
\begin{aligned}
i_{t}= & B_{1} E_{t}^{C B}\left[i_{t+1}\right]+B_{2} E_{t-1}^{C B}\left[i_{t}\right]+B_{3} i_{t-1}+B_{4} i_{t-2} \\
& +B_{5} E_{t}^{C B}\left[\pi_{t+2}\right]+B_{6} E_{t}^{C B}\left[\pi_{t+1}\right]+B_{7} E_{t-1}^{C B}\left[\pi_{t+1}\right]+B_{8} E_{t-1}^{C B}\left[\pi_{t}\right]+B_{9} \pi_{t}+B_{10} \pi_{t-1}+B_{11} \pi_{t-2} \\
& +B_{12} E_{t}^{C B}\left[x_{t+2}\right]+B_{13} E_{t}^{C B}\left[x_{t+1}\right]+B_{14} E_{t-1}^{C B}\left[x_{t+1}\right]+B_{15} E_{t-1}^{C B}\left[x_{t}\right]+B_{16} x_{t}+B_{17} x_{t-1}+B_{18} x_{t-2},
\end{aligned}
$$

where the coefficients are as follows.

$$
\begin{aligned}
& B_{1} \equiv \beta \bar{\gamma}_{b}\left(1+\tilde{\gamma}_{b}\right)^{-1}, B_{2} \equiv-\bar{\gamma}_{f} \bar{\gamma}_{b} \bar{\kappa}_{b}\left(1+\tilde{\gamma}_{b}\right)^{-1}\left(\bar{\kappa}_{b}+\bar{\gamma}_{b} \bar{\kappa}_{c}\right)^{-1}, \\
& B_{3} \equiv \beta^{-1}\left(1+\bar{\gamma}_{f}+\bar{\kappa}_{c} \sigma^{-1}\right)\left(1+\tilde{\gamma}_{b}\right)^{-1}, B_{4} \equiv-\bar{\gamma}_{f} \beta^{-2}\left(1+\tilde{\gamma}_{b}\right)^{-1} .
\end{aligned}
$$

\section{B2. Gianonni and Woodford (2003) model}

Giannoni and Woodford assume that each period a randomly chosen fraction $1-\alpha$ of all prices are reconsidered, and that these are set optimally; but the price of each good $i$ that is not reconsidered is adjusted to the indexation rule

$$
\log p_{t}(i)=\log p_{t-1}(i)+(1-\lambda) \pi_{t-1},
$$

where $\lambda \in[0,1]$ denotes the degree of automatic indexation to the most recently available inflation measure. In this setting, Giannoni and Woodford then derive the following Phillips curve and social loss function.

$$
\begin{gathered}
\pi_{t}=\gamma_{b} \pi_{t-1}+\gamma_{f} E_{t}\left[\pi_{t+1}\right]+\widetilde{\kappa} x_{t}, \\
E_{0}\left[\sum_{t=0}^{\infty} \beta^{t}\left[\left\{\pi_{t}-(1-\lambda) \pi_{t-1}\right\}^{2}+w_{x} x_{t}^{2}+w_{i} i_{t}^{2}\right]\right],
\end{gathered}
$$

where $\gamma_{b} \equiv \frac{1-\lambda}{1+\beta(1-\lambda)}, \quad \gamma_{f} \equiv \frac{\beta}{1+\beta(1-\lambda)}, \quad \widetilde{\kappa} \equiv \gamma_{\kappa} \kappa, \quad \gamma_{\kappa} \equiv \frac{1}{1+\beta(1-\lambda)}$,

and the other coefficients are the same as those in our model.

Taking expectations of social loss function (B16) conditional on $\Omega_{0}^{C B}$ yields

$$
E_{0}^{C B}\left[\begin{array}{l}
\left\{\pi_{0}-(1-\bar{\lambda}) \pi_{-1}\right\}^{2}+v_{\lambda} \pi_{-1}^{2}+w_{x} x_{0}^{2}+w_{i} i_{0}^{2}+\beta\left(V_{0}^{C B}\left[\pi_{1}\right]+w_{x} V_{0}^{C B}\left[x_{1}\right]\right) \\
+\sum_{t=1}^{\infty} \beta^{t}\left[\begin{array}{l}
\left\{E_{t-1}^{C B}\left[\pi_{t}-(1-\bar{\lambda}) \pi_{t-1}\right]\right\}^{2}+v_{\lambda} \pi_{t-1}^{2}+w_{x}\left(E_{t-1}^{C B}\left[x_{t}\right]\right)^{2}+w_{i} i_{t}^{2} \\
+\beta\left(V_{t}^{C B}\left[\pi_{t+1}\right]+w_{x} V_{t}^{C B}\left[x_{t+1}\right]\right)
\end{array}\right]
\end{array}\right] .
$$

From the IS curve (3) and the Phillips curve (B15), it follows that the conditional variance of the output gap takes the same form as (18) and that of inflation is given by

$$
V_{t}^{C B}\left[\pi_{t+1}\right]=v_{\lambda}\left(\pi_{t}-\beta^{-1} \pi_{t-1}\right)^{2}+\text { t.i.p. }
$$

The optimal plan then minimizes social welfare function (B18) with respect to the endogenous variables subject to conditional variances (18)(B19), constraint (20), and the following constraint (B20). 


$$
\pi_{t}=\bar{\gamma}_{b} \pi_{t-1}+\bar{\gamma}_{f} E_{t}^{C B}\left[\pi_{t+1}\right]+\bar{\gamma}_{\kappa} \kappa x_{t},
$$

where $\bar{\gamma}_{b} \equiv \frac{1-\bar{\lambda}}{1+\beta(1-\bar{\lambda})}, \quad \bar{\gamma}_{f} \equiv \frac{\beta}{1+\beta(1-\bar{\lambda})}, \quad$ and $\quad \bar{\gamma}_{\kappa} \equiv \frac{1}{1+\beta(1-\bar{\lambda})}$.

The associated Lagrangian is given by

$$
E_{0}^{C B}\left[\begin{array}{c}
v_{\lambda} \pi_{-1}^{2}+\left\{\pi_{0}-(1-\bar{\lambda}) \pi_{-1}\right\}^{2}+w_{x} x_{0}^{2}+w_{i} i_{0}^{2} \\
+v_{\lambda} \beta\left\{\pi_{0}^{2}+\left(1+w_{x} \sigma^{-2}\right)\left(\pi_{0}-\beta^{-1} \pi_{-1}\right)^{2}\right\} \\
+\sum_{t=1}^{\infty} \beta^{t}\left[\begin{array}{l}
\left\{E_{t-1}^{C B}\left[\pi_{t}-(1-\bar{\lambda}) \pi_{t-1}\right]\right\}^{2}+w_{x}\left(E_{t-1}^{C B}\left[x_{t}\right]\right)^{2}+w_{i} i_{t}^{2} \\
+v_{\lambda} \beta\left\{\pi_{t}^{2}+\left(1+w_{x} \sigma^{-2}\right)\left(\pi_{t}-\beta^{-1} \pi_{t-1}\right)^{2}\right\}
\end{array}\right] \\
+2 \sum_{t=0}^{\infty} \beta^{t}\left[\phi_{x, t}\left\{x_{t}-x_{t+1}+\sigma^{-1}\left(i_{t}-\pi_{t+1}\right)\right\}+\phi_{\pi, t}\left(\pi_{t}-\bar{\gamma}_{b} \pi_{t-1}-\bar{\gamma}_{f} \pi_{t+1}-\bar{\gamma}_{\kappa} \kappa x_{t}\right)\right]
\end{array}\right],
$$

where $\phi_{x, t}$ and $\phi_{\pi, t}$ are Lagrange multipliers on (20)(B20) in period $t$, respectively. The first-order conditions with respect to $\pi_{t}, x_{t}$, and $i_{t}$ are, in every period $t \geq 0$,

$$
\begin{aligned}
& \left\{\pi_{t}-(1-\bar{\lambda}) \pi_{t-1}\right\}-\beta(1-\bar{\lambda})\left\{E_{t}^{C B}\left[\pi_{t+1}\right]-(1-\bar{\lambda}) \pi_{t}\right\}+\phi_{\pi, t}-\beta \bar{\gamma}_{b} E_{t}\left[\phi_{\pi, t+1}\right]-\bar{\gamma}_{f} \beta^{-1} \phi_{\pi, t-1} \\
& \quad-\beta^{-1} \sigma^{-1} \phi_{x, t-1}+v_{\lambda} \beta\left\{\pi_{t}+\left(1+w_{x} \sigma^{-2}\right)\left\{\left(\pi_{t}-\beta^{-1} \pi_{t-1}\right)-\left(E_{t}^{C B}\left[\pi_{t+1}\right]-\beta^{-1} \pi_{t}\right)\right\}=0,\right. \\
& w_{x} x_{t}-\bar{\gamma}_{\kappa} \kappa \phi_{\pi, t}+\phi_{x, t}-\beta^{-1} \phi_{x, t-1}=0 \\
& w_{i} i_{t}+\sigma^{-1} \phi_{x, t}=0
\end{aligned}
$$

together with initial conditions $\phi_{x,-1}=\phi_{\pi,-1}=0$. Combining the conditions (B22)(B23) (B24) to eliminate all multipliers yields the following interest rate rule that implements the optimal plan.

$$
\begin{aligned}
i_{t}= & \beta \bar{\gamma}_{b}\left(1+\bar{\gamma}_{b}\right)^{-1} E_{t}^{C B}\left[i_{t+1}\right]+\beta^{-1}\left(1+\bar{\gamma}_{b}\right)^{-1}\left(1+\bar{\gamma}_{f}+\bar{\gamma}_{\kappa} \kappa \sigma^{-1}\right) i_{t-1}-\bar{\gamma}_{f} \beta^{-2}\left(1+\bar{\gamma}_{b}\right)^{-1} i_{t-2} \\
& +\bar{\gamma}_{\kappa} \kappa \sigma^{-1} w_{i}^{-1}\left(1+\bar{\gamma}_{b}\right)^{-1}\left[\left\{\pi_{t}-(1-\bar{\lambda}) \pi_{t-1}\right\}-\beta(1-\bar{\lambda})\left\{E_{t}^{C B}\left[\pi_{t+1}\right]-(1-\bar{\lambda}) \pi_{t}\right\}\right] \\
& +v_{\lambda} \beta \bar{\gamma}_{\kappa} \kappa \sigma^{-1} w_{i}^{-1}\left(1+\bar{\gamma}_{b}\right)^{-1}\left[\pi_{t}+\left(1+w_{x} \sigma^{-2}\right)\left\{\left(\pi_{t}-\beta^{-1} \pi_{t-1}\right)-\left(E_{t}^{C B}\left[\pi_{t+1}\right]-\beta^{-1} \pi_{t}\right)\right\}\right] \\
& -\beta \bar{\gamma}_{b} w_{x} \sigma^{-1} w_{i}^{-1}\left(1+\bar{\gamma}_{b}\right)^{-1} E_{t}^{C B}\left[x_{t+1}\right]+w_{x} \sigma^{-1} w_{i}^{-1}\left(1+\bar{\gamma}_{b}\right)^{-1} x_{t}-\bar{\gamma}_{f} w_{x} \beta^{-1} \sigma^{-1} w_{i}^{-1}\left(1+\bar{\gamma}_{b}\right)^{-1} x_{t-1} .
\end{aligned}
$$

\section{Appendix C. Optimal Plan under Uncertainty on Rule-of-Thumb Consumers}

Taking expectations of social loss function (33) conditional on $\Omega_{0}^{C B}$ leads to

$$
E_{0}^{C B}\left[\begin{array}{l}
\pi_{0}^{2}+\lambda_{x} x_{0}^{2}+\bar{w}_{\Delta y}\left(y_{0}-y_{-1}\right)^{2}+w_{i} i_{0}^{2}+\beta\left(V_{0}^{C B}\left[\pi_{1}\right]+w_{x} V_{0}^{C B}\left[x_{1}\right]+\bar{w}_{\Delta y} V_{0}^{C B}\left[y_{1}\right]\right) \\
+\sum_{t=1}^{\infty} \beta^{t}\left(\begin{array}{l}
\left(E_{t-1}^{C B}\left[\pi_{t}\right]\right)^{2}+w_{x}\left(E_{t-1}^{C B}\left[x_{t}\right]\right)^{2}+\bar{w}_{\Delta y}\left(E_{t-1}^{C B}\left[y_{t}-y_{t-1}\right]\right)^{2}+w_{i} i_{t}^{2} \\
+\beta\left(V_{t}^{C B}\left[\pi_{t+1}\right]+w_{x} V_{t}^{C B}\left[x_{t+1}\right]+\bar{w}_{\Delta y} V_{t}^{C B}\left[y_{t+1}\right]\right)
\end{array}\right),
\end{array}\right]
$$

where $\bar{w}_{\Delta y} \equiv E_{t}^{C B}\left[w_{\Delta y}\right]$. From Phillips curve (11) and IS curve (30), it follows that the conditional variance of inflation is independent of monetary policy, and that those of 
output and the output gap are given by

$$
\begin{gathered}
V_{t}^{C B}\left[y_{t+1}\right]=v_{\psi}\left\{y_{t}-y_{t-1}-\sigma^{-1} i_{t}+\beta^{-1} \sigma^{-1} \pi_{t}-\kappa \beta^{-1} \sigma^{-1} x_{t}+\left(1-\rho_{g}\right) g_{t}\right\}^{2}+t . i . p ., \\
V_{t}^{C B}\left[x_{t+1}\right]=V_{t}^{C B}\left[y_{t+1}\right]+t . i . p .
\end{gathered}
$$

The optimal policy plan then minimizes social loss function $(\mathrm{C} 1)$ with respect to the endogenous variables subject to conditional variances $(\mathrm{C} 2)(\mathrm{C} 3)$ and the following constraints.

$$
\begin{gathered}
y_{t}=(1-\bar{\delta}) y_{t-1}+\bar{\delta} E_{t}^{C B}\left[y_{t+1}\right]-\bar{\psi} \bar{\delta} \sigma^{-1}\left(i_{t}-E_{t}^{C B}\left[\pi_{t+1}\right]\right)+\bar{\psi} \bar{\delta}\left(1-\rho_{g}\right) g_{t}, \text { where } \bar{\delta} \equiv 1 /(2-\bar{\psi}), \\
\pi_{t}=\beta E_{t}^{C B}\left[\pi_{t+1}\right]+\kappa x_{t} .
\end{gathered}
$$

The equations (C4) (C5) are obtained by taking expectations of IS curve (30) and Phillips curve (11) conditional on the central bank's information set $\Omega_{t}^{C B} \cdot{ }^{26}$

Then, the associated Lagrangian is given by

$$
E_{0}^{C B}\left[\begin{array}{l}
\pi_{0}^{2}+w_{x} x_{0}^{2}+\bar{w}_{\Delta y}\left(y_{0}-y_{-1}\right)^{2}+w_{i} i_{0}^{2} \\
+v_{\psi} \beta\left(w_{x}+\bar{w}_{\Delta y}\right)\left\{y_{0}-y_{-1}-\sigma^{-1} i_{0}+\beta^{-1} \sigma^{-1} \pi_{0}-\kappa \beta^{-1} \sigma^{-1} x_{0}+\left(1-\rho_{g}\right) g_{0}\right\}^{2} \\
+\sum_{t=0}^{\infty} \beta^{t}\left[\begin{array}{l}
\left(E_{t-1}^{C B}\left[\pi_{t}\right]\right)^{2}+w_{x}\left(E_{t-1}^{C B}\left[x_{t}\right]\right)^{2}+\bar{w}_{\Delta y}\left(E_{t-1}^{C B}\left[\hat{Y}_{t}-\hat{Y}_{t-1}\right]\right)^{2}+w_{i} i_{t}^{2} \\
+v_{\psi} \beta\left(w_{x}+\bar{w}_{\Delta y}\right)\left\{y_{t}-y_{t-1}-\sigma^{-1} i_{t}+\beta^{-1} \sigma^{-1} \pi_{t}-\kappa \beta^{-1} \sigma^{-1} x_{t}+\left(1-\rho_{g}\right) g_{t}\right\}^{2}
\end{array}\right] \\
+2 \sum_{t=0}^{\infty} \beta^{t}\left[\phi_{y, t}\left\{y_{t}-(1-\bar{\delta}) y_{t-1}-\bar{\delta} y_{t+1}+\bar{\psi} \bar{\delta} \sigma^{-1}\left(\hat{i}_{t}-\pi_{t+1}\right)\right\}+\phi_{\pi, t}\left(\pi_{t}-\beta \pi_{t+1}-\kappa x_{t}\right)\right]
\end{array}\right],
$$

where $\phi_{y, t}$ and $\phi_{\pi, t}$ are Lagrange multipliers on $(\mathrm{C} 4)(\mathrm{C} 5)$ in period $t$, respectively. The first-order conditions with respect to $\pi_{t}, y_{t}$, and $i_{t}$ are, in every period $t \geq 0$,

$$
\begin{aligned}
\pi_{t} & +\phi_{\pi, t}-\phi_{\pi, t-1}-\bar{\psi} \bar{\delta} \beta^{-1} \sigma^{-1} \phi_{y, t-1} \\
& +v_{\psi} \sigma^{-1}\left(w_{x}+\bar{w}_{\Delta y}\right)\left\{y_{t}-y_{t-1}-\sigma^{-1} i_{t}+\beta^{-1} \sigma^{-1} \pi_{t}-\kappa \beta^{-1} \sigma^{-1} x_{t}+\left(1-\rho_{g}\right) g_{t}\right\}=0,
\end{aligned}
$$

\footnotetext{
${ }^{26}$ Taking expectations of IS curve (30) conditional on the central bank's information set $\Omega_{t}^{C B}$ leads to $y_{t}=E_{t}^{C B}[1-\delta] y_{t-1}+E_{t}^{C B}[\delta] \cdot E_{t}^{C B}\left[E_{t}\left(y_{t+1}\right)\right]+\operatorname{Cov}_{t}^{C B}\left[\delta, E_{t}\left(y_{t+1}\right)\right]-E_{t}^{C B}[1 / \tilde{\sigma}]\left(i_{t}-E_{t}^{C B}\left[\pi_{t+1}\right]\right)-E_{t}^{C B}[\psi / 2-\psi]\left(\rho_{g}-1\right) g_{t}$
}

The third term on the right-hand side can be rearranged as follows.

$$
\begin{aligned}
\operatorname{Cov}_{t}^{C B}[\delta, & \left.E_{t}\left(y_{t+1}\right)\right]=\operatorname{Cov}_{t}^{C B}\left[\delta, \frac{1}{\delta} y_{t}-\frac{1-\delta}{\delta} y_{t-1}+\frac{1}{\delta \tilde{\sigma}}\left(i-E_{t}\left[\pi_{t+1}\right]\right)+\frac{\psi\left(\rho_{g}-1\right)}{\delta(2-\psi)} g_{t}\right] \\
= & \left(1-E_{t}^{C B}[\delta] \cdot E_{t}^{C B}\left[\frac{1}{\delta}\right]\right) y_{t}-\left(E_{t}^{C B}[1-\delta]-E_{t}^{C B}[\delta] \cdot E_{t}^{C B}\left[\frac{1-\delta}{\delta}\right]\right) y_{t-1} \\
& -\left(E_{t}^{C B}\left[\frac{1}{\tilde{\sigma}}\right]-E_{t}^{C B}[\delta] \cdot E_{t}^{C B}\left[\frac{1}{\delta \tilde{\sigma}}\right]\right)\left(i-E_{t}^{C B}\left[\pi_{t+1}\right]\right)+\left(E_{t}^{C B}\left[\frac{\psi}{2-\psi}\right]-E_{t}^{C B}[\delta] \cdot E_{t}^{C B}\left[\frac{\psi}{(2-\psi) \delta}\right]\right)\left(\rho_{g}-1\right) g_{t}
\end{aligned}
$$

Substituting this conditional covariance into the above equation and then rearranging the resulting equation yields $(\mathrm{C} 4)$. 


$$
\begin{aligned}
& w_{x} x_{t}+\bar{w}_{\Delta y}\left(y_{t}-y_{t-1}\right)-\beta \bar{w}_{\Delta y}\left(E_{t}^{C B}\left[y_{t+1}\right]-y_{t}\right)-\kappa \phi_{\pi, t}+\phi_{y, t}-\bar{\delta} \beta^{-1} \phi_{y, t-1}-\beta(1-\bar{\delta}) E_{t}^{C B}\left[\phi_{y, t+1}\right] \\
& \quad+v_{\psi}\left(w_{x}+\bar{w}_{\Delta y}\right)\left(\beta-\kappa \sigma^{-1}\right)\left\{y_{t}-y_{t-1}-\sigma^{-1} i_{t}+\beta^{-1} \sigma^{-1} \pi_{t}-\kappa \beta^{-1} \sigma^{-1} x_{t}+\left(1-\rho_{g}\right) g_{t}\right\} \\
& \quad-v_{\psi} \beta^{2}\left(w_{x}+\bar{w}_{\Delta y}\right) E_{t}^{C B}\left[y_{t+1}-y_{t}-\sigma^{-1} i_{t+1}+\beta^{-1} \sigma^{-1} \pi_{t+1}-\kappa \beta^{-1} \sigma^{-1} x_{t+1}+\left(1-\rho_{g}\right) g_{t+1}\right]=0, \\
& \lambda_{i} i_{t}+\bar{\psi} \bar{\delta} \sigma^{-1} \phi_{y, t} \\
& \quad-v_{\psi} \beta \sigma^{-1}\left(w_{x}+\bar{w}_{\Delta y}\right)\left\{y_{t}-y_{t-1}-\sigma^{-1} i_{t}+\beta^{-1} \sigma^{-1} \pi_{t}-\kappa \beta^{-1} \sigma^{-1} x_{t}+\left(1-\rho_{g}\right) g_{t}\right\}=0,
\end{aligned}
$$

together with initial conditions $\phi_{x,-1}=\phi_{\pi,-1}=0$. Combining the conditions $(\mathrm{C} 7)(\mathrm{C} 8)(\mathrm{C} 9)$ to eliminate all multipliers yields the following interest rate rule that implements the optimal plan.

$$
\begin{aligned}
i_{t}= & C_{1}\left(E_{t}^{C B}\left[i_{t+1}\right]-E_{t-1}^{C B}\left[i_{t}\right]\right)+C_{2} i_{t-1}+C_{3}\left(i_{t-1}-i_{t-2}\right) \\
& +C_{4}\left(E_{t}^{C B}\left[\pi_{t+1}\right]-E_{t-1}^{C B}\left[\pi_{t}\right]\right)+C_{5} \pi_{t}+C_{6}\left(\pi_{t}-\pi_{t-1}\right)+C_{7}\left(\pi_{t-1}-\pi_{t-2}\right) \\
& +C_{8}\left(E_{t}^{C B}\left[x_{t+1}\right]-E_{t-1}^{C B}\left[x_{t}\right]\right)+C_{9}\left(x_{t}-x_{t-1}\right)+C_{10}\left(x_{t-1}-x_{t-2}\right) \\
& +C_{11}\left\{\left(E_{t}^{C B}\left[y_{t+1}\right]-y_{t}\right)-\left(E_{t-1}^{C B}\left[y_{t}\right]-y_{t-1}\right)\right\}+C_{12}\left\{\left(y_{t}-y_{t-1}\right)-\left(y_{t-1}-y_{t-2}\right)\right\} \\
& +C_{13}\left\{\left(y_{t-1}-y_{t-2}\right)-\left(y_{t-2}-y_{t-3}\right)\right\}+C_{14}\left(g_{t}-g_{t-1}\right)+C_{15}\left(g_{t-1}-g_{t-2}\right),
\end{aligned}
$$

where the coefficients are as follows.

$$
\begin{aligned}
& C_{1} \equiv \beta\left[1-\bar{\delta}\left\{1-v_{\psi} \beta \bar{\psi} \bar{\delta} \sigma^{-2} \widetilde{w}_{i}^{-1}\left(w_{x}+\bar{w}_{\Delta y}\right)\right\}\right], \quad C_{2} \equiv 1+w_{i} \kappa \bar{\psi} \bar{\delta} \beta^{-1} \sigma^{-1} \widetilde{w}_{i}^{-1}, \\
& C_{3} \equiv \bar{\delta} \beta^{-1}\left\{1-v_{\psi} \beta \bar{\psi} \bar{\delta} \sigma^{-2} \widetilde{w}_{i}^{-1}\left(w_{x}+\bar{w}_{\Delta y}\right)\right\}, \quad C_{4} \equiv-v_{\psi} \sigma^{2} \beta^{-1} \widetilde{w}_{i}^{-1}\left(w_{x}+\bar{w}_{\Delta y}\right)\{1-\bar{\delta}(1-\bar{\psi})\}, \\
& C_{5} \equiv \kappa \bar{\psi} \bar{\delta} \sigma^{-1} \widetilde{w}_{i}^{-1}, \quad C_{6} \equiv v_{\psi} \sigma^{2} \widetilde{w}_{i}^{-1}(1+\bar{\psi} \bar{\delta})\left(w_{x}+\bar{w}_{\Delta y}\right), \quad C_{7} \equiv-v_{\psi} \bar{\delta} \sigma^{2} \beta^{-1} \widetilde{w}_{i}^{-1}\left(w_{x}+\bar{w}_{\Delta y}\right), \\
& C_{8} \equiv v_{\psi} \beta \kappa \sigma^{2} \widetilde{w}_{i}^{-1}\left(w_{x}+\bar{w}_{\Delta y}\right)\{1-\bar{\delta}(1-\bar{\psi})\}, \quad C_{9} \equiv \bar{\psi} \bar{\delta} \sigma^{-1} \widetilde{w}_{i}^{-1}\left\{w_{x}-v_{\psi} \kappa \sigma^{-1}\left(1+\bar{\psi}^{-1} \bar{\delta}^{-1}\right)\left(w_{x}+\bar{w}_{\Delta y}\right)\right\}, \\
& C_{10} \equiv v_{\psi} \bar{\delta} \kappa \sigma^{2} \beta^{-1} \widetilde{w}_{i}^{-1}\left(w_{x}+\bar{w}_{\Delta y}\right), \quad C_{11} \equiv-\beta \bar{\psi} \bar{\delta} \sigma^{-1} \widetilde{w}_{i}^{-1}\left[\bar{w}_{\Delta y}+v_{\psi} \beta\left(w_{x}+\bar{w}_{\Delta y}\right)\left\{1+\bar{\psi}^{-1}\left(\bar{\delta}^{-1}-1\right)\right\}\right], \\
& C_{12} \equiv \bar{\psi} \bar{\delta} \sigma^{-1} \widetilde{w}_{i}^{-1}\left\{\bar{w}_{\Delta y}+v_{\psi} \beta\left(1+\bar{\psi}^{-1} \bar{\delta}^{-1}\right)\left(w_{x}+\bar{w}_{\Delta y}\right)\right\}, \quad C_{13} \equiv-v_{\psi} \bar{\delta} \sigma^{-1} \widetilde{w}_{i}^{-1}\left(w_{x}+\bar{w}_{\Delta y}\right), \\
& C_{14} \equiv v_{\psi} \beta \sigma^{-1} \widetilde{w}_{i}^{-1}\left(1-\rho_{g}\right)\left(w_{x}+\bar{w}_{\Delta y}\right)\left\{\beta \rho_{g} \bar{\delta}+\left(1-\beta \rho_{g}\right)(1+\bar{\psi} \bar{\delta})\right\}, \\
& C_{15} \equiv-v_{\psi} \bar{\delta} \sigma^{-1} \widetilde{w}_{i}^{-1}\left(1-\rho_{g}\right)\left(w_{x}+\bar{w}_{\Delta y}\right), \quad \text { where } \quad \widetilde{w}_{i} \equiv\left\{w_{i}+v_{\psi} \beta \sigma^{-2}(1+\bar{\psi} \bar{\delta})\left(w_{x}+\bar{w}_{\Delta y}\right)\right\} .
\end{aligned}
$$




\section{References}

Amato, J.D., Laubach, T., 2003. Rule-of-thumb behavior and monetary policy. European Economic Review 47, 791-831.

Blinder, A.S. 1998. Central Banking in Theory and Practice. MIT Press, Cambridge, MA.

Brainard, W., 1967. Uncertainty and the effectiveness of policy. American Economic Review 57, 411-425.

Calvo, G.A., 1983. Staggered prices in a utility-maximizing framework. Journal of Monetary Economics 12, 383-398.

Christiano, L.J., Eichenbaum, M.S., Evans, C.L., 2001. Nominal rigidities and the dynamic effects of a shock to monetary policy. NBER Working Paper No. 8403.

Craine, R., 1979. Optimal monetary policy with uncertainty. Journal of Economic Dynamics and Control 1, 59-83.

Estrella, A., Mishkin, F.S., 1999. Rethinking the role of NAIRU in monetary policy: Implications of model formulation and uncertainty. In: Taylor, J.B., ed., Monetary Policy Rules. University of Chicago Press, Chicago, IL, 405-430.

Estrella, A., Fuhrer, J.C., 2002. Dynamic inconsistencies: Counterfactual implications of a class of rational expectations models. American Economic Review 92, 1013-1028.

Fuhrer, J.C., 1997. The (un)importance of forward-looking behavior in price specifications. Journal of Money, Credit and Banking 29, 338-350.

Friedman, M., 1969. The optimum quantity of money. In: Friedman, M., The Optimum Quantity of Money and Other Essays. Aldine Publishing Company, Chicago, IL, 1-50.

Galí, J., Gertler, M., 1999. Inflation dynamics: A structural econometric analysis, Journal of Monetary Economics 44, 195-222.

Galí, J., Gertler, M., López-Salido, J.D., 2001. European inflation dynamics. European Economic Review 45, 1237-1270.

Giannoni, M.P., 2000. Optimal interest-rate rules in a forward-looking model, and inflation stabilization versus price-level stabilization. Working Paper, Federal Reserve Bank of New York.

Giannoni, M.P., 2002. Does model uncertainty justify caution? Robust optimal monetary policy in a forward-looking model. Macroeconomic Dynamics 6, 111-144.

Giannoni, M.P., Woodford, M., 2003. Optimal inflation targeting rules. Forthcoming in: Bernanke, B.S., Woodford, M., eds., Inflation Targeting, University of Chicago Press, Chicago, IL.

Hall, S., Salmon, C., Yates, T., Batini, N., 1999. Uncertainty and simple monetary policy rules: An illustration for the United Kingdom. Bank of England Working Paper No. 96.

Kimura, T., Kurozumi, T., 2004. Effectiveness of history-dependent monetary policy. 
Forthcoming in Journal of the Japanese and International Economies.

Levin A.T., Williams, J.C., 2003. Parameter uncertainty and the central bank's objective function. mimeo.

Mankiw, G., 2001. The inexorable and mysterious tradeoff between inflation and unemployment. Economic Journal 111, C45-C61.

Martin, B., Salmon, C., 1999. Should uncertainty monetary policy-makers do less? Bank of England Working Paper No. 99.

McCallum, B.T., 1983. On nonuniqueness in linear rational expectations models: An attempt at perspective. Journal of Monetary Economics 11, 139-168.

McCallum, B.T., 2003a. The unique minimum state variable RE solution is E-stable in all well formulated linear models. NBER Working Paper No. 9960.

McCallum, B.T., 2003b. On the relationship between determinate and MSV solutions in linear RE models. Working Paper, Carnegie Mellon University.

Rotemberg, J.J., Woodford, M., 1997. An optimization-based econometric framework for the evaluation of monetary policy. In: Bernanke, B.S., Rotemberg, J.J., eds., NBER Macroeconomics Annual 1997. MIT Press, Cambridge, MA, 297-346.

Rotemberg, J.J., Woodford, M., 1999. Interest rate rules in an estimated sticky price model. In: Taylor, J.B., ed., Monetary Policy Rules. University of Chicago Press, Chicago, IL, 57-119.

Rudebusch, G.D., 2002. Assessing nominal income rules for monetary policy with model and data uncertainty. Economic Journal 112, 402-432.

Roberts, J.M., 1995. New Keynesian economics and the Phillips curve. Journal of Money, Credit and Banking 27, 975-984.

Roberts, J.M., 2001. How well does the new Keynesian sticky-price model fit the data? Finance and Economics Discussion Series 2001-13, Federal Reserve Board.

Svensson, L.E.O., 1997. Inflation forecast targeting: Implementing and monitoring inflation targets. European Economic Review 41, 1111-1146.

Svensson, L.E.O., 1999, Inflation targeting: Some extensions. Scandinavian Journal of Economics 101, 337-361.

Sack, B., 2000. Does the Fed act gradually? A VAR analysis, Journal of Monetary Economics 46, 229-256.

Söderström, U., 2002. Monetary policy with uncertain parameters. Scandinavian Journal of Economics 104, 125-145.

Steinsson, J., 2003. Optimal monetary policy in an economy with inflation persistence. Journal of Monetary Economics 50, 1425-1456.

Vestin, D., 2000. Price-level targeting versus inflation targeting in a forward-looking model. Riksbank Working Paper No. 106. 
Walsh, C., 2003a. Speed limit policies: The output gap and optimal monetary policy. American Economic Review 93, 265-278.

Walsh, C., 2003b. Implications of a changing economic structure for the strategy of monetary policy. Federal Reserve Bank of Kansas City's Jackson Hall Conference.

Woodford, M., 1999. Optimal monetary policy inertia. NBER Working Paper No. 7261.

Woodford, M., 2003. Interest and Price: Foundations of a Theory of Monetary Policy. Princeton University Press, Princeton, NJ. 


\section{Figure 1. Beta Distribution}

(1)Mean $=0.75$

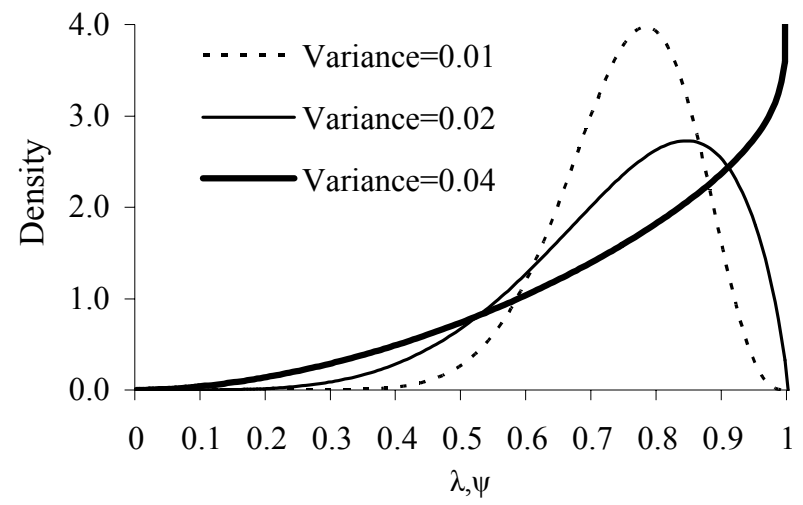

(2)Mean $=0.5$

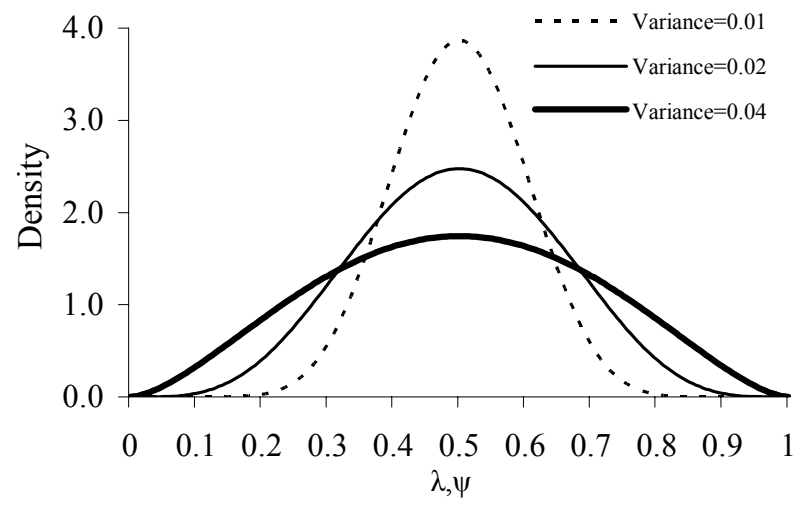

(3)Mean $=0.25$

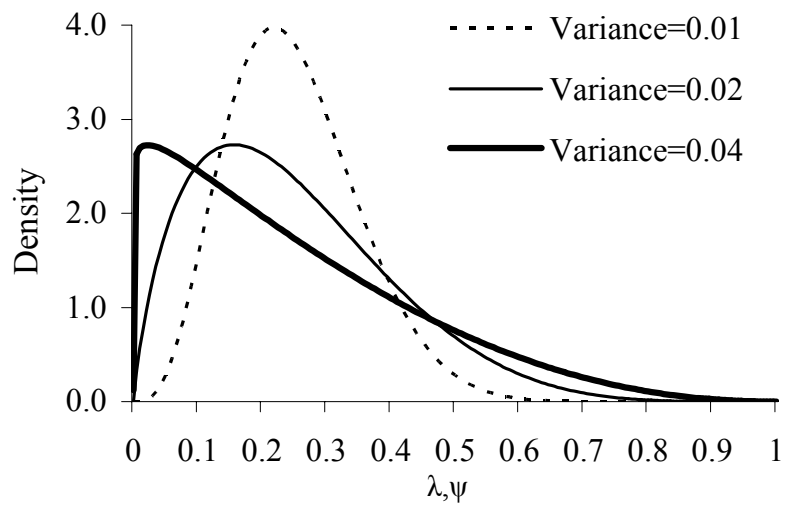


Figure 2. Social Welfare Weight on Variability of Change in Inflation
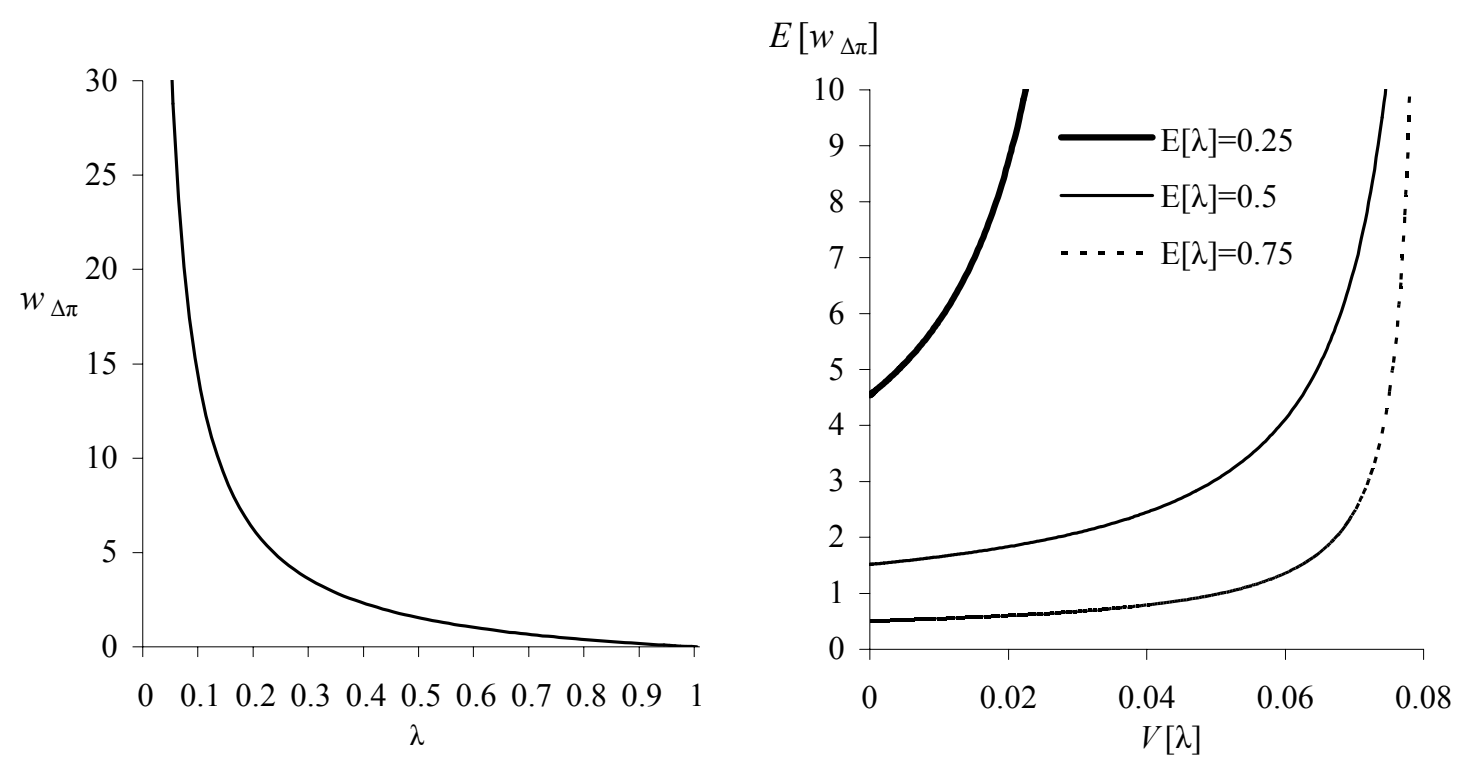
Figure 3. Initial Policy Response to a Natural Rate of Interest Shock

Uncertainty about Rule-of-Thumb Price Setters

$w_{i}=0.236$

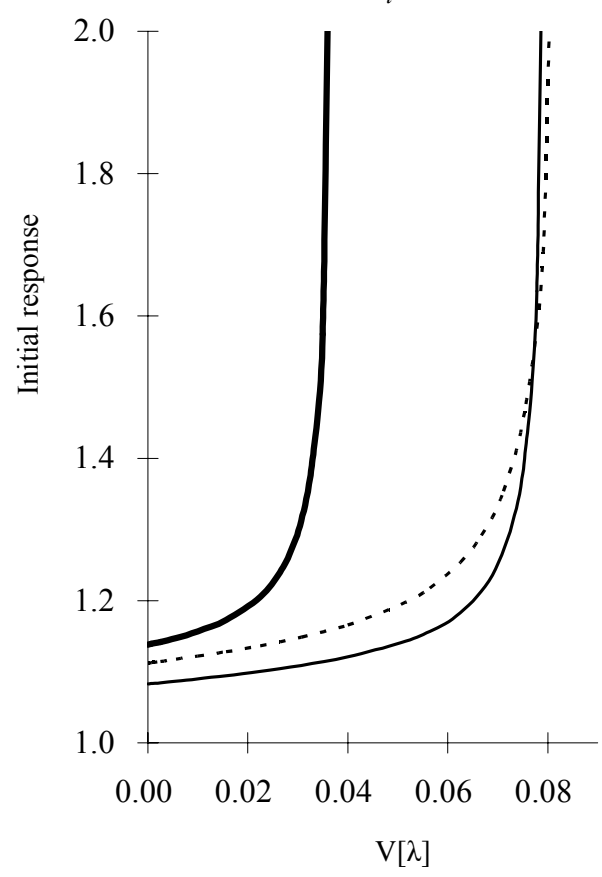

$-E[\lambda]=0.25$
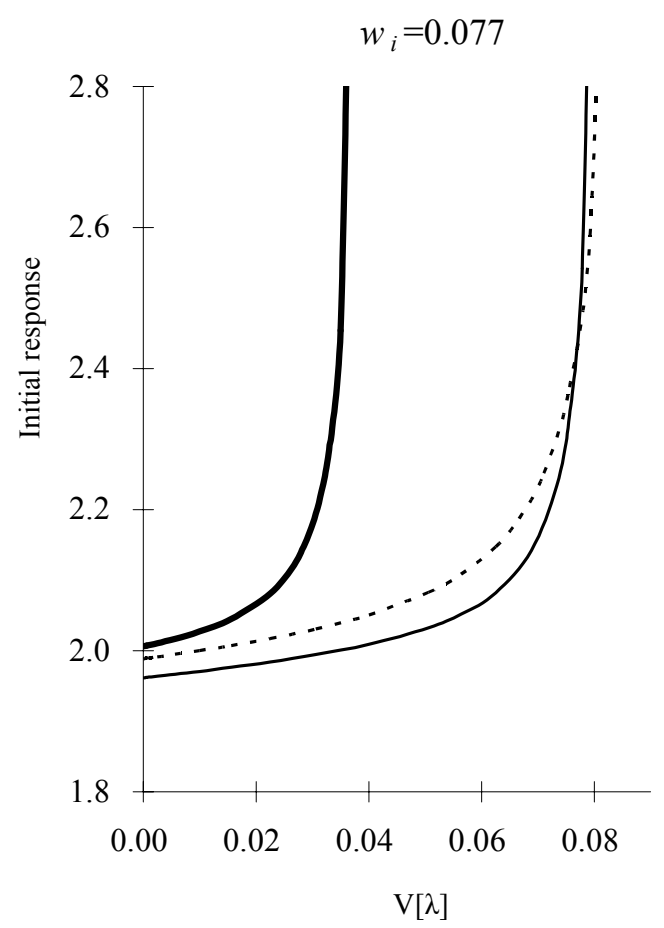

$\cdots \cdot \mathrm{E}[\lambda]=0.5$

$-\mathrm{E}[\lambda]=0.75$

(Note) Initial policy response shows the parameter $a_{1}$ in MSV REE process of interest rate (26), which is multiplied by $4 \times \operatorname{sd}\left[r_{t}{ }^{n}\right]$ in order to adjust the scale. (annualised percentage) 
Figure 4. Decomposition of Effect of Uncertainty on Initial Policy Response

Uncertainty about Rule-of-Thumb Price Setters
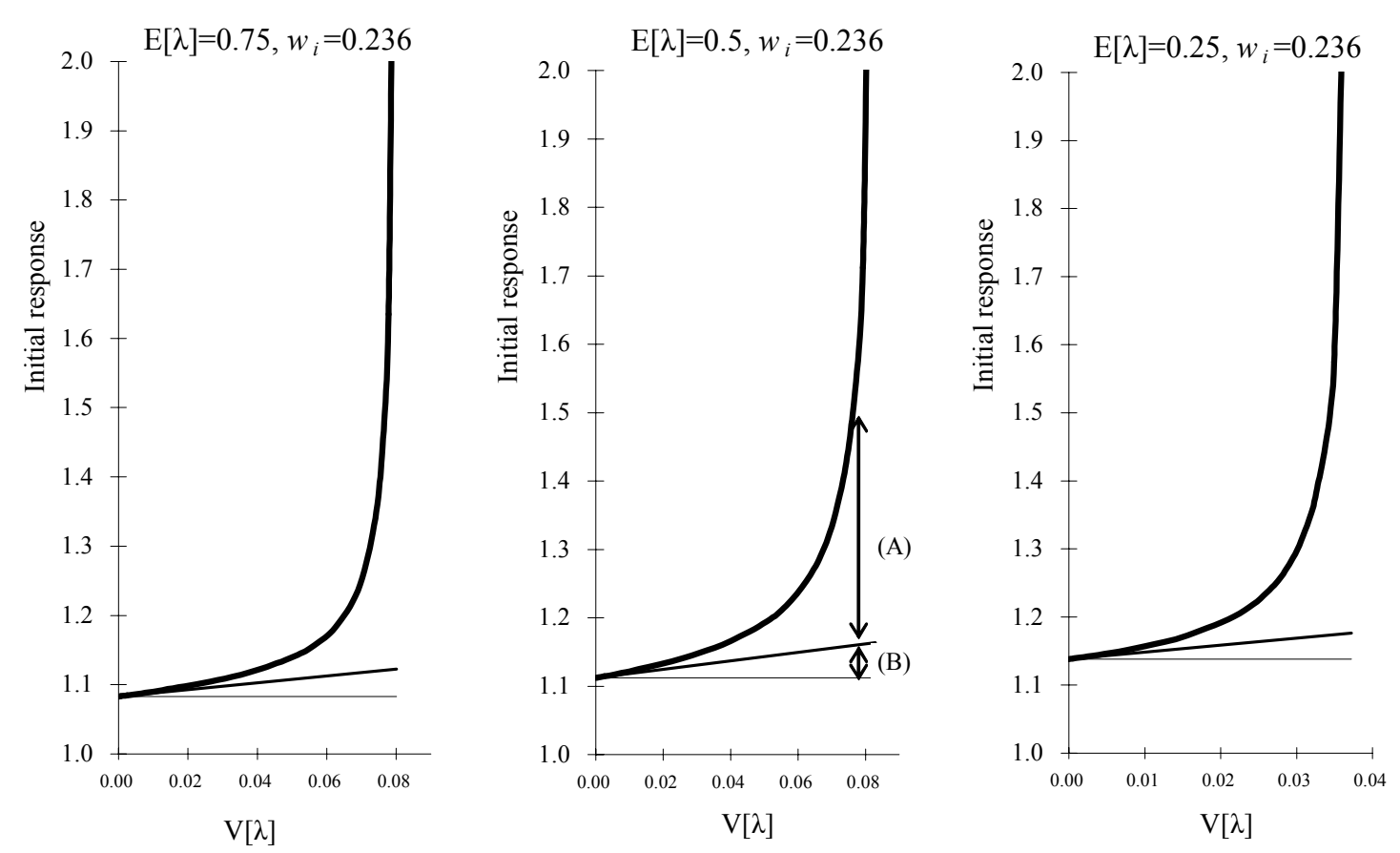

— Policy response under total uncertainty

— Policy response under uncertainty about inflation dynamics (with fixed loss-function weight)

Certainty equivalence (with known paramter $\lambda$ )

(A) Effect of uncertainty about loss function

(B) Effect of uncertainty about inflation dyanamics 
Figure 5. Impulse Response to a Natural Rate of Interest Shock Under Uncertainty on Rule-of-Thumb Price Setting $(E[\lambda]=0.5)$
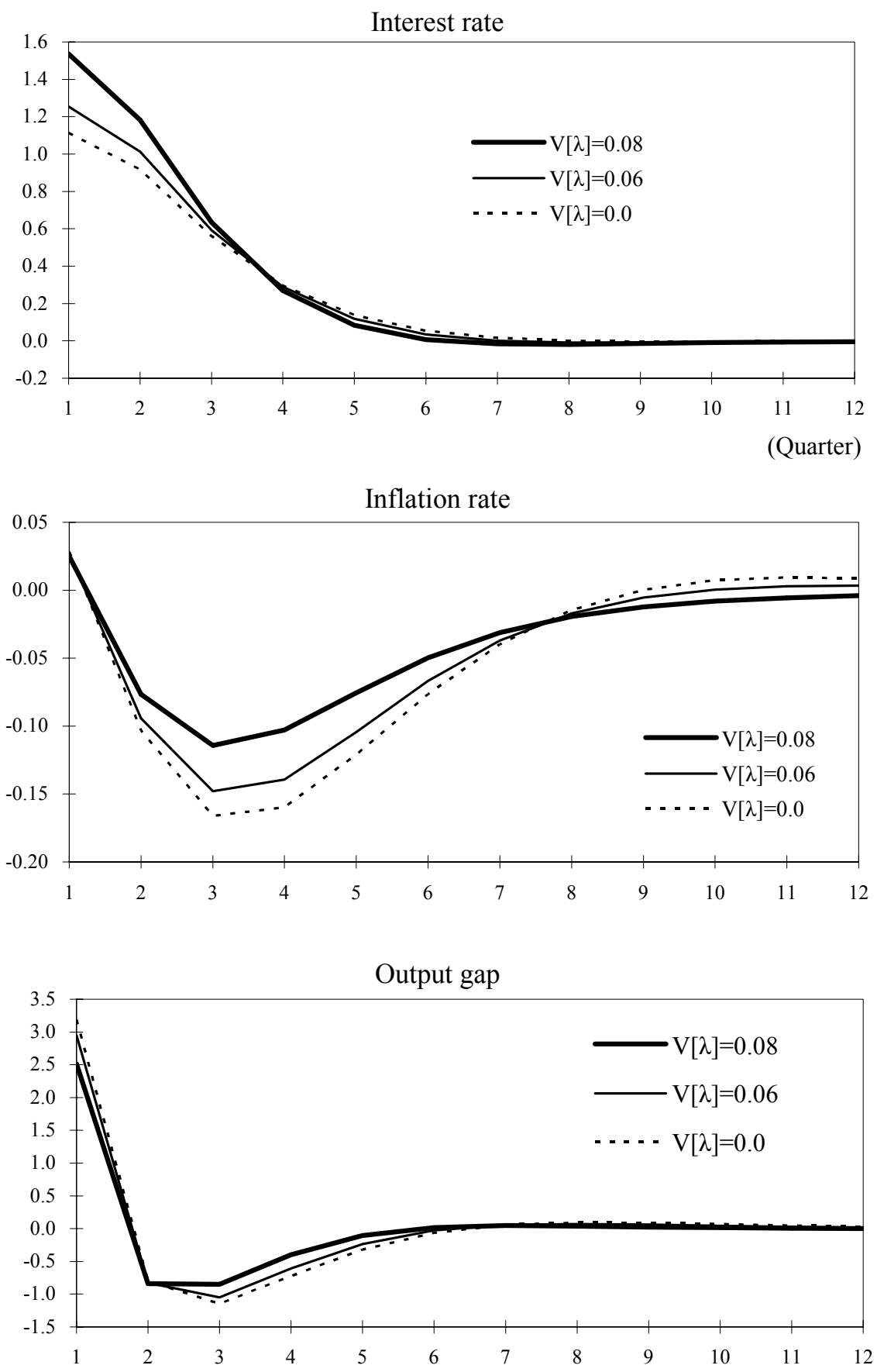

(Note) Inflation and the interest rate are expressed in annualized percentages, the output gap in percentages. 
Figure 6. Impulse Response to a Natural Rate of Interest Shock Under Uncertainty on Rule-of-Thumb Price Setting $(E[\lambda]=0.25)$
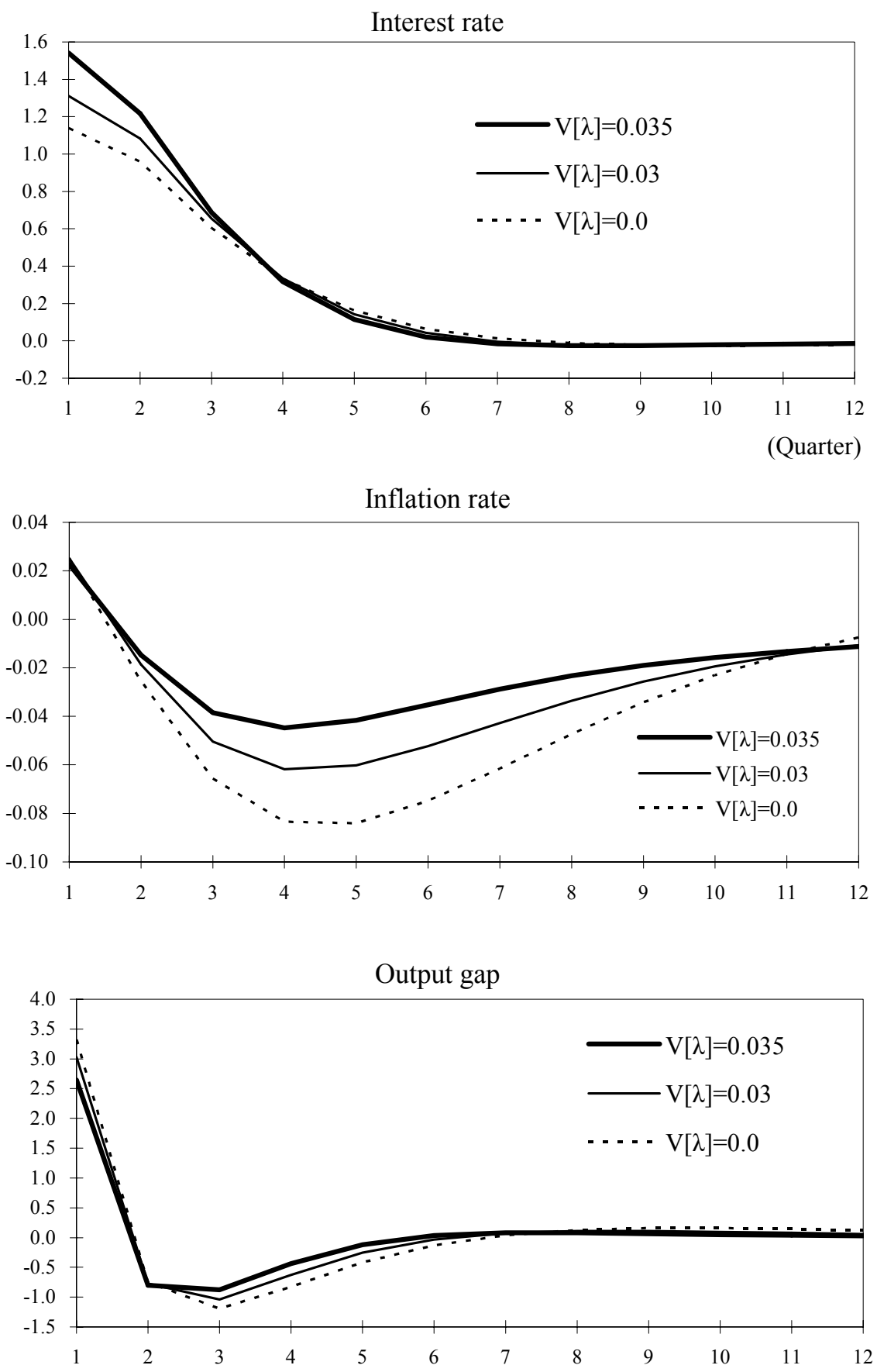

(Note) Inflation and the interest rate are expressed in annualized percentages, the output gap in percentages. 
Figure 7. Coefficients on Lagged Interest Rate in Optimal Policy Plan

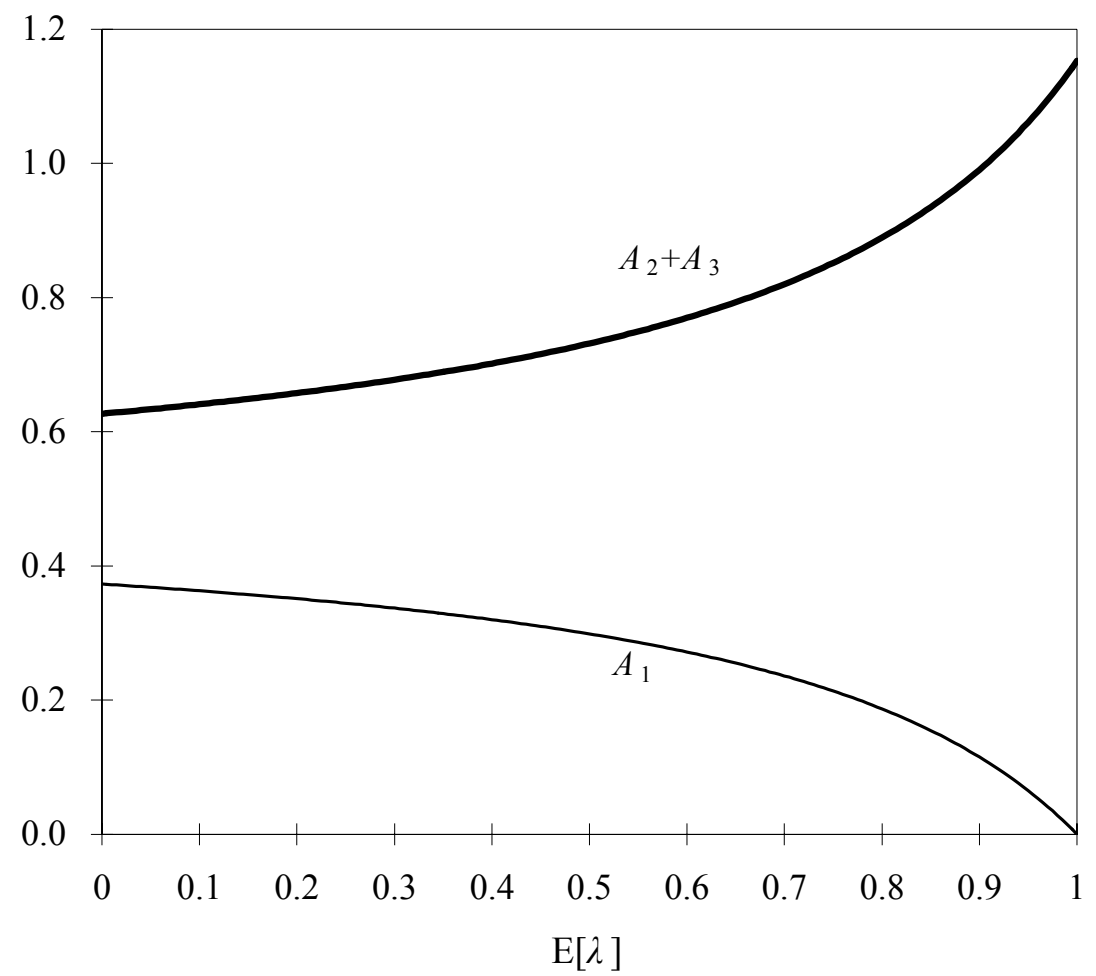


Figure 8. Variance Frontier

Uncertainty about Rule-of-Thumb Price Setters

$(\mathrm{NU}=$ No Uncertainty, $\quad \mathrm{HU}=$ High Uncertainty $)$
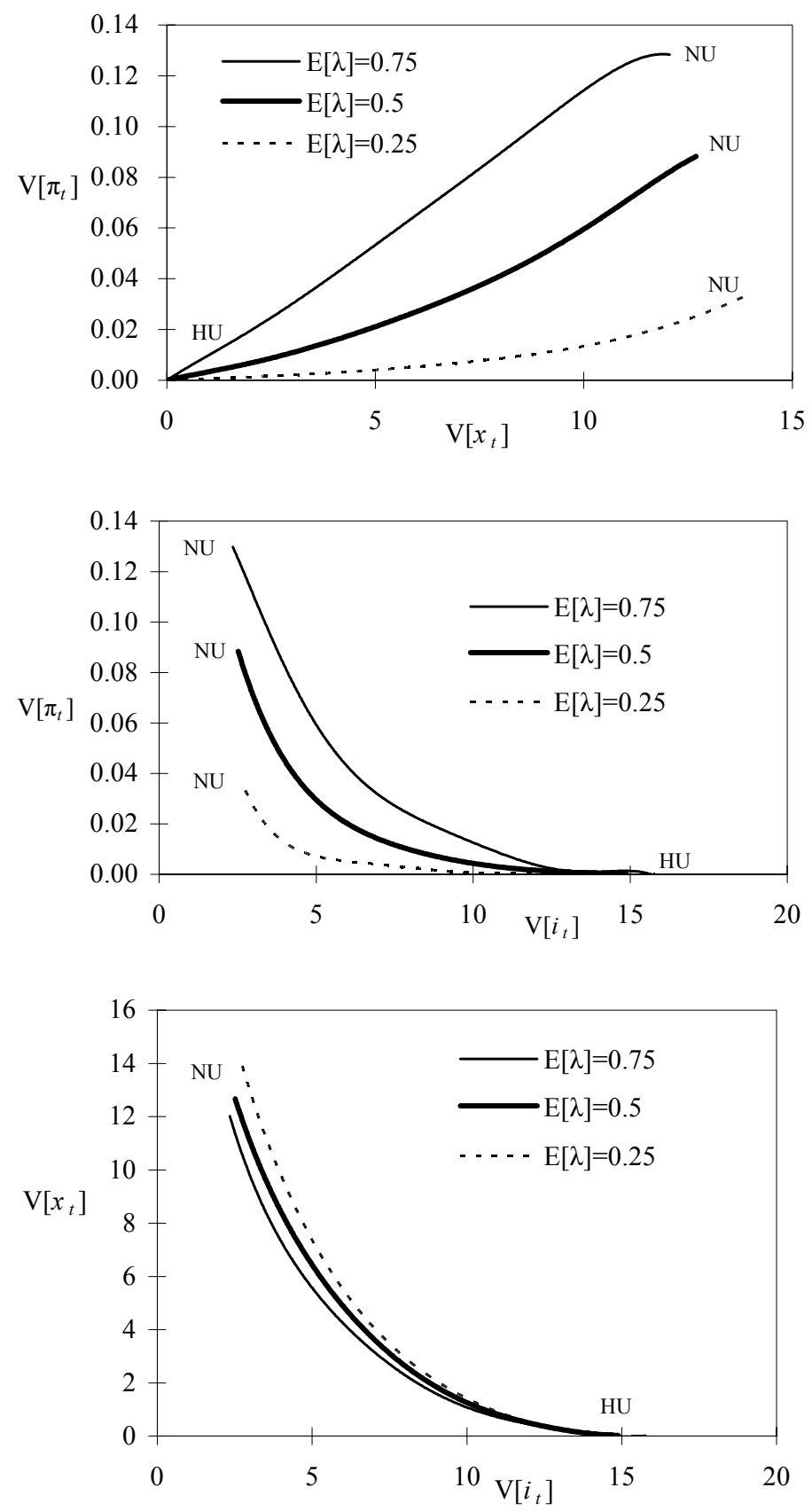
Figure 9. Expected Social Loss

Uncertainty about Rule-of-Thumb Price Setters

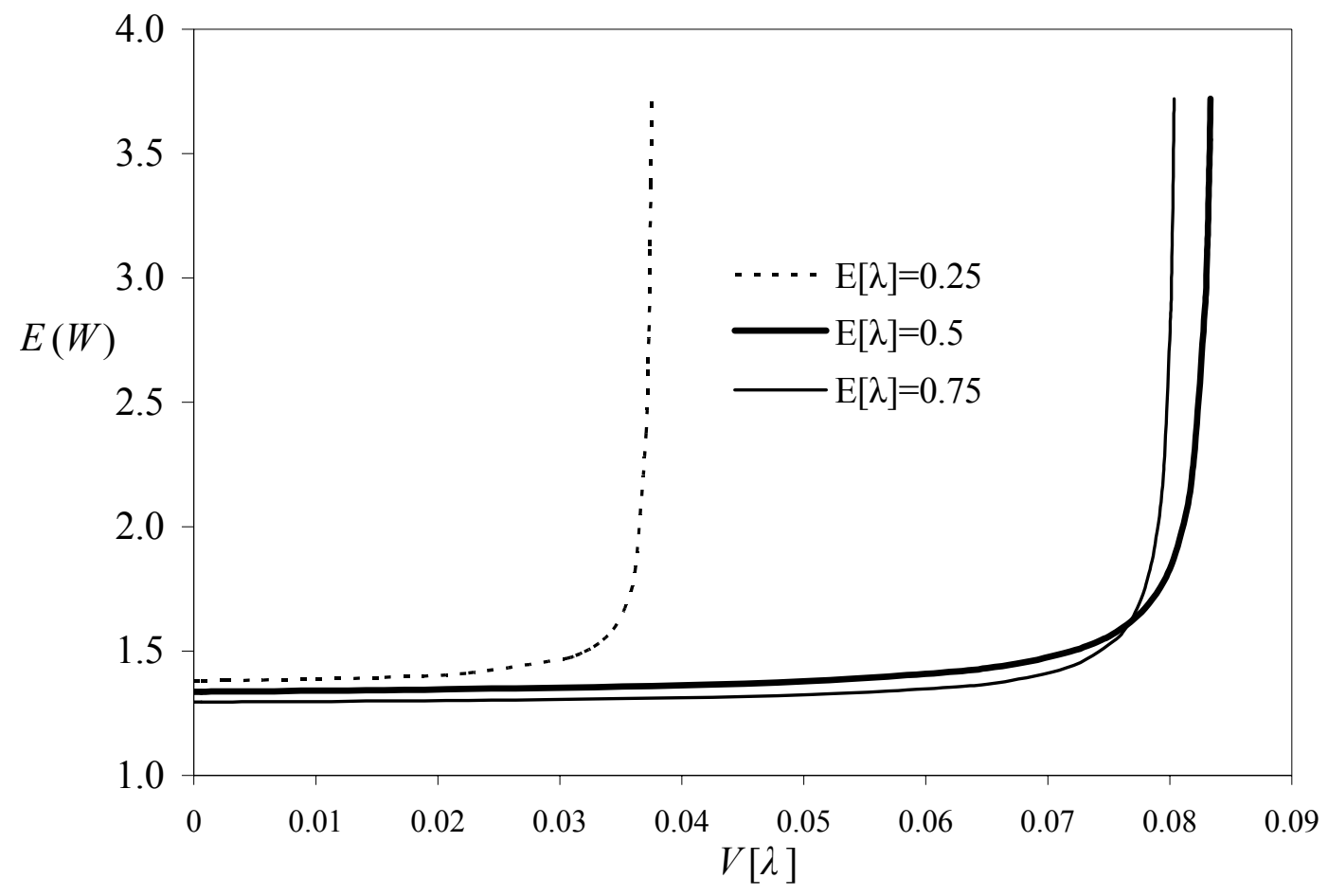




\section{Figure 10. Initial Policy Response to a Natural Rate of Interest Shock in Alternative Models}

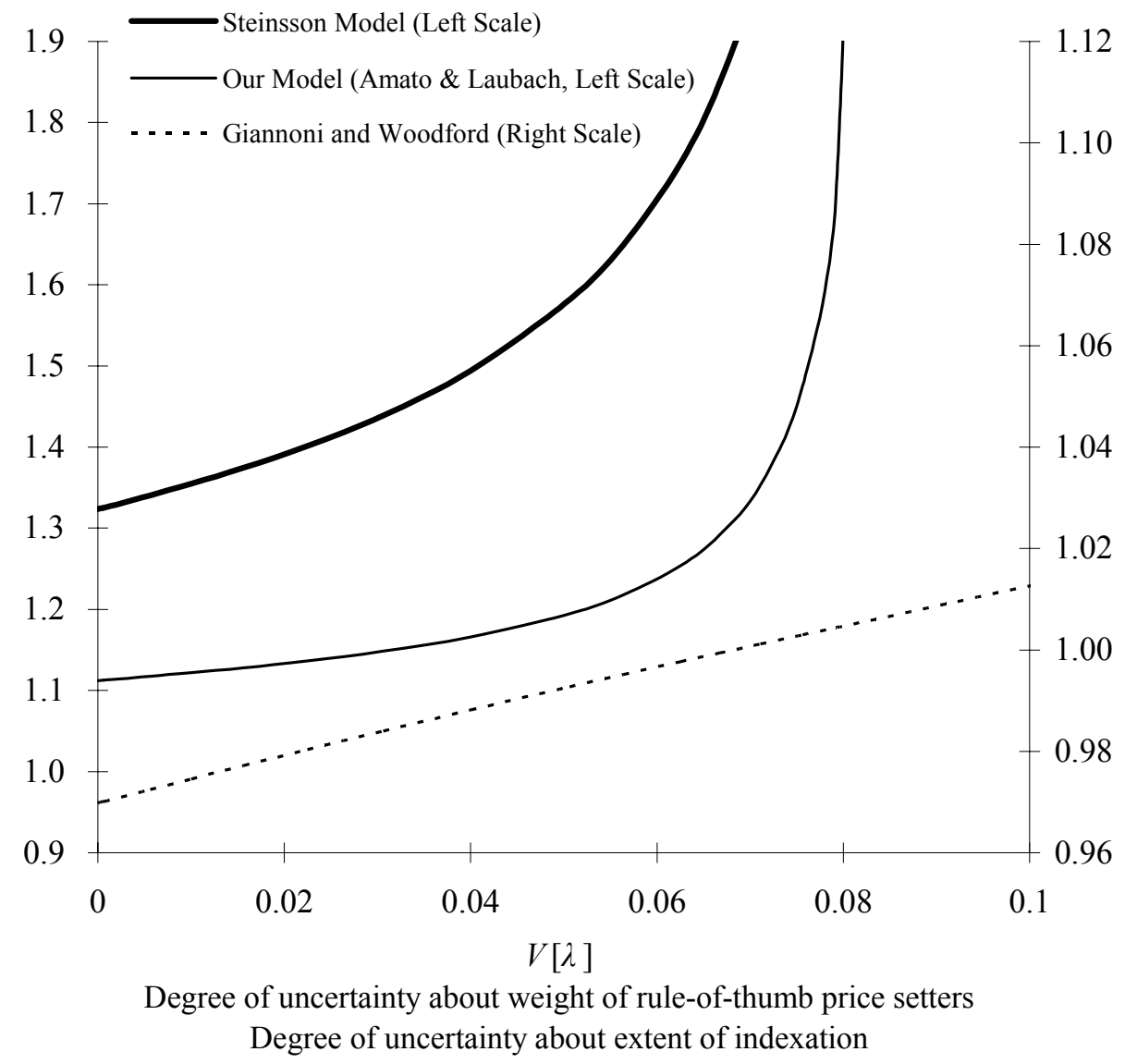

(Note1) Parameters are calibrated to equal those used in Section 4.1. The central bank's prior belief on the parameter $\lambda$ is assumed to be formed with a beta distribution. The figure shows the case of $w_{i}=0.236$ and $\lambda=0.5$. In Steinsson's model, we set $\delta=0.052$, following Steinsson (2003). See Appendix B for details.

(Note2) Initial policy response shows the parameter on $r_{t}{ }^{n}$ in MSV REE process of interest rate, which is multiplied by $4 \times \mathrm{sd}\left[r_{t}{ }^{n}\right]$ in order to adjust the scale. (annualized percentage) 
Figure 11. Initial Policy Response to a Marginal Utility of Consumption Shock

Uncertainty about Rule-of-Thumb Consumers
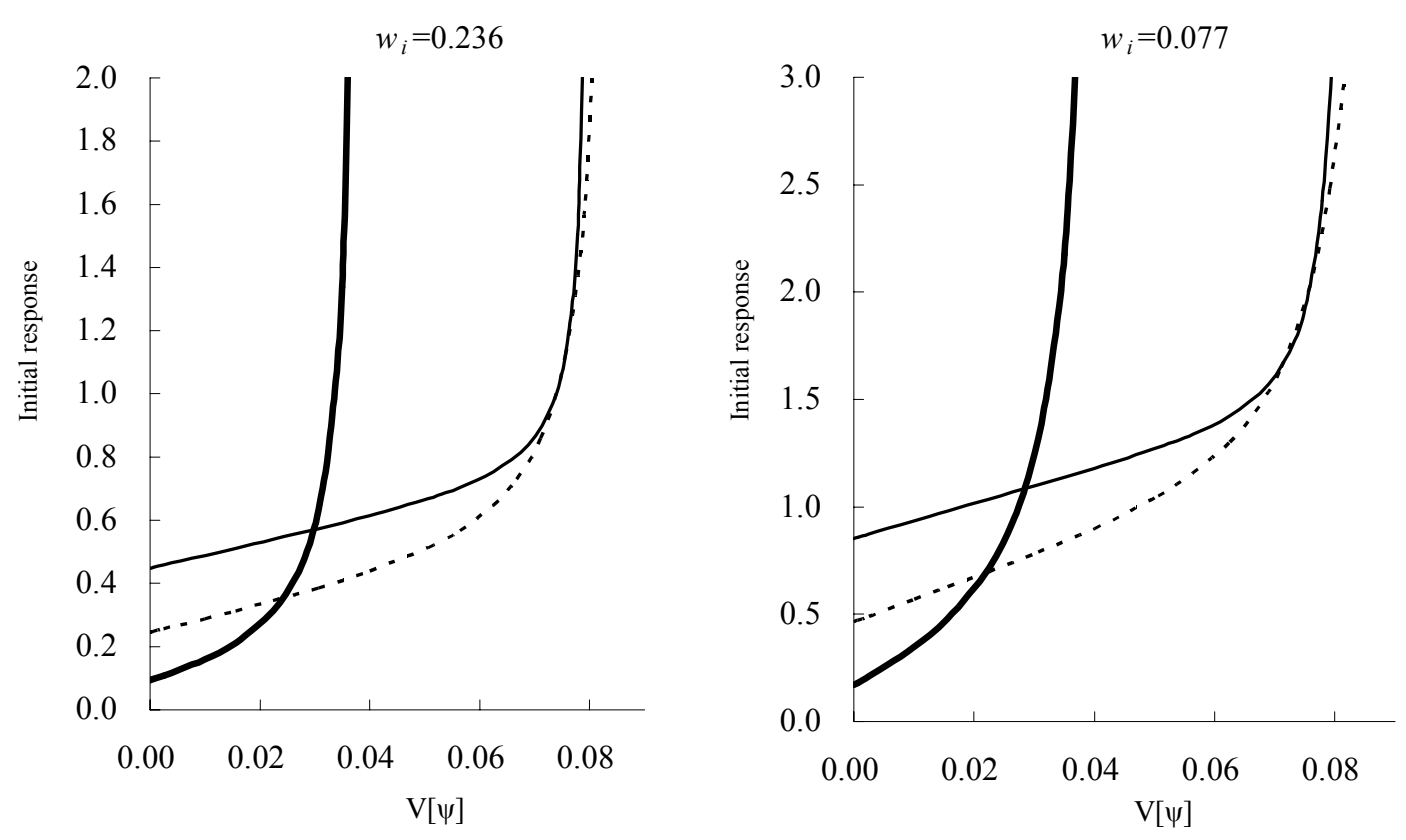

$-\mathrm{E}[\psi]=0.75$

- . - $\mathrm{E}[\psi]=0.5$

$-\mathrm{E}[\psi]=0.25$

(Note) Initial policy response shows the parameter on $g_{t}$ in MSV REE process of interest rate, which is multiplied by $4 \times \operatorname{sd}\left[g_{t}\right]$ in order to adjust the scale. (annualized percentage). 


\title{
Figure 12. Decomposition of Effects of Uncertainty on Initial Policy Response
}

\author{
Uncertainty about Rule-of-Thumb Consumers
}

$\mathrm{E}[\psi]=0.75, w_{i}=0.236$

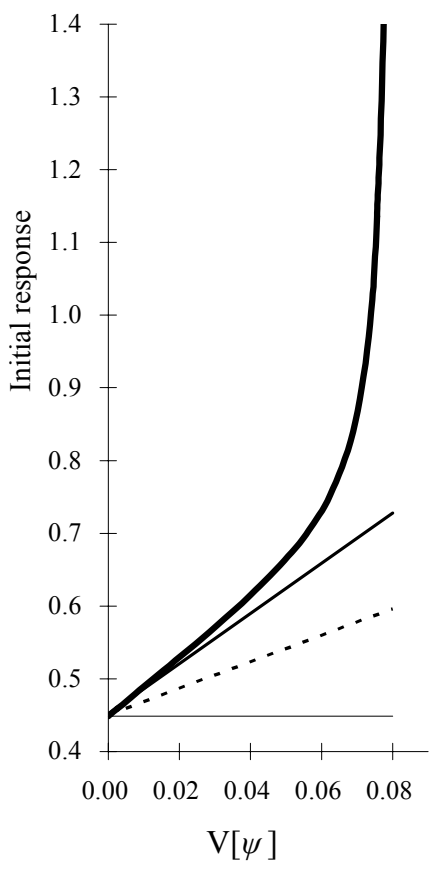

$\mathrm{E}[\psi]=0.5, w_{i}=0.236$

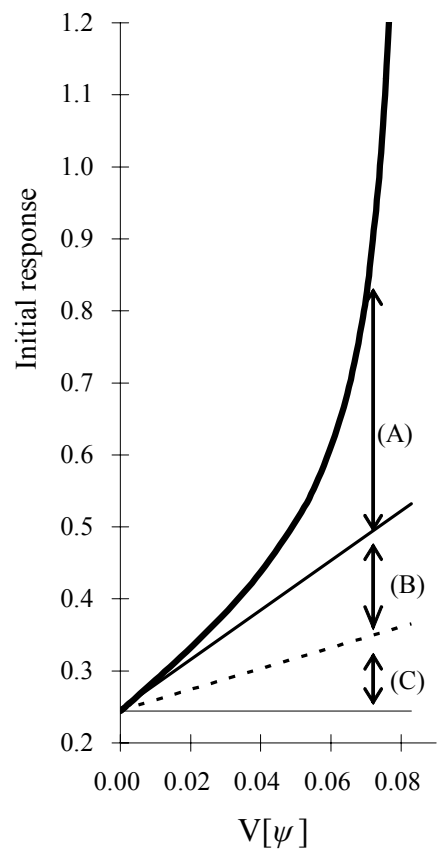

$\mathrm{E}[\psi]=0.25, w_{i}=0.236$

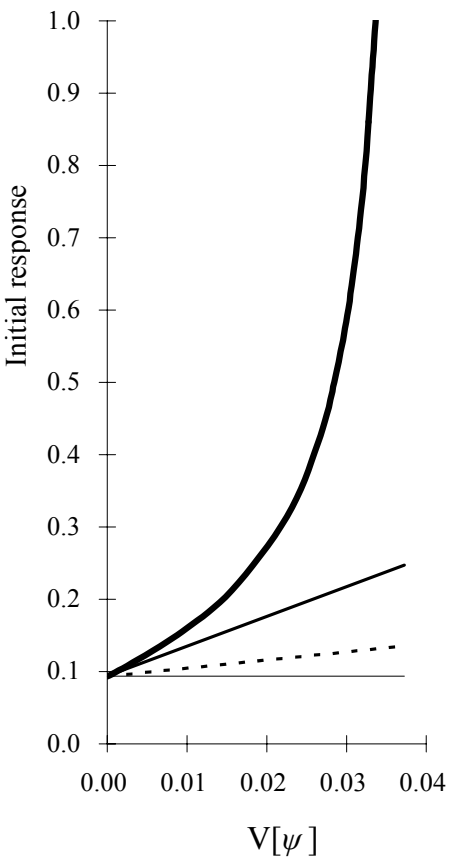

— Policy response under total uncertainty

- Policy response under uncertainty with fixed weight of the social loss function

-... - Policy response under uncertainty with fixed weight of the social loss function and fixed transmission of shock

_ Certainty equivalence (with known paramter $\psi$ )

(A) Effect of uncertainty about loss function

(B) Effect of positive correlation between policy mutiplier and transmission of shock

(C) Effect of uncertainty about output dyanamics 